\title{
Slo1 is the principal potassium channel of human spermatozoa
}

\author{
Nadja Mannowetz ${ }^{1}$, Natasha M Naidoo ${ }^{1 \dagger}$, Seung-A Sara Choo ${ }^{1 \dagger}$, James F Smith ${ }^{2}$, \\ Polina V Lishko ${ }^{1 *}$
}

${ }^{1}$ Department of Molecular and Cell Biology, University of California, Berkeley, Berkeley, United States; ${ }^{2}$ Department of Urology, University of California, San Francisco, San Francisco, United States

\begin{abstract}
Mammalian spermatozoa gain competence to fertilize an oocyte as they travel through the female reproductive tract. This process is accompanied by an elevation of sperm intracellular calcium and a membrane hyperpolarization. The latter is evoked by $\mathrm{K}^{+}$efflux; however, the molecular identity of the potassium channel of human spermatozoa (hKSper) is unknown. Here, we characterize hKSper, reporting that it is regulated by intracellular calcium but is insensitive to intracellular alkalinization. We also show that human KSper is inhibited by charybdotoxin, iberiotoxin, and paxilline, while mouse KSper is insensitive to these compounds. Such unique properties suggest that the Slo1 ion channel is the molecular determinant for hKSper. We show that Slo1 is localized to the sperm flagellum and is inhibited by progesterone. Inhibition of hKSper by progesterone may depolarize the spermatozoon to open the calcium channel CatSper, thus raising $\left[\mathrm{Ca}^{2+}\right]$ to produce hyperactivation and allowing sperm to fertilize an oocyte.
\end{abstract}

DOI: 10.7554/eLife.01009.001

*For correspondence: lishko@ berkeley.edu

tThese authors contributed equally to this work

Competing interests: The authors declare that no competing interests exist.

Funding: See page 15

Received: 28 May 2013

Accepted: 02 September 2013

Published: 08 October 2013

Reviewing editor: Richard Aldrich, The University of Texas at Austin, United States

(c) Copyright Mannowetz et al. This article is distributed under the terms of the Creative Commons Attribution License, which permits unrestricted use and redistribution provided that the original author and source are credited.

\section{Introduction}

Mammalian spermatozoa are unable to fertilize the oocyte immediately after their deposit into the female reproductive tract. Instead, they have to undergo a final maturation termed capacitation, during which spermatozoa gain competence to fertilize (Chang, 1951; Austin, 1952). Early stages of capacitation include the bicarbonate-mediated acceleration of sperm beat frequency and an increase in linear motility (Visconti et al., 1995a, 1995b, 1999, 2002; Chen et al., 2000; Wennemuth et al., 2003; Wandernoth et al., 2010; Mannowetz et al., 2011). Late stages of capacitation compriseamongst others-intracellular alkalinization (Meizel and Deamer, 1978), elevation of intracellular $\mathrm{Ca}^{2+}$ (Visconti et al., 2002), and membrane hyperpolarization (Zeng et al., 1995; Arnoult et al., 1996; Demarco et al., 2003). These interdependent processes are regulated by sperm ion channels, of which Hv1 and CatSper (Cation channel of sperm) were identified as the major $\mathrm{H}^{+}$and $\mathrm{Ca}^{2+}$ channels of human spermatozoa (Ren et al., 2001; Kirichok et al., 2006; Lishko and Kirichok, 2010; Lishko et al., 2010, 2011; Ren and Xia, 2010; Strunker et al., 2011; Lishko et al., 2012). However, the identity of the principal human $\mathrm{K}^{+}$channel remained elusive.

Potassium channels are indispensable for normal sperm physiology, since they regulate membrane potential and cell motility. Recently, an alkalinization-sensitive sperm $\mathrm{K}^{+}$channel, encoded by the kcnu1 gene (also known as Slo3), was shown to be essential for male fertility in mice (Schreiber et al., 1998; Navarro et al., 2007; Santi et al., 2010; Zeng et al., 2011). It has been assumed, but never proven, that the $\mathrm{K}^{+}$channel of human sperm has a similar molecular identity. The Slo gene family is represented by Slo1, Slo2, and Slo3 (Wei et al., 2005). These channels possess seven transmembrane helices S0-S6, with the S1-S6 helices exhibiting homology to classic voltage-gated $\mathrm{K}^{+}$channels. They are tetramers of $\alpha$ subunits, with the $\mathrm{K}^{+}$-selective pore formed by S5 and S6 (Adelman et al., 1992; Butler et al., 1993; Diaz et al., 1998; Cui and Aldrich, 2000). In addition, the Slo1 channel contains 
eLife digest The sperm cells that are released into the female reproductive tract when a mammal ejaculates, are not capable of fertilizing an egg right away, so they must go through a process called maturation. The early stages of this process involve interactions with the seminal fluid that increase the motility of the sperm cells, and the latter stages involve interactions with the walls of the reproductive tract and vaginal secretions to ensure that the sperm cells move toward the egg. Many of these interactions involve positive ions entering and leaving the sperm cells via ion channels.

The properties of the ion channels that allow protons and calcium ions to move into and out of human sperm cells are well understood, but little is known about the channels that control the movement of the potassium (K) ions. At first it was assumed that the molecular structure of these channels was similar to that of the Slo3 potassium channel in mouse sperm, but crucial differences between human and mouse sperm cells have been reported in recent years.

Now Mannowetz et al. have shown that the potassium channel in human sperm is opened by increased levels of calcium ions inside the sperm cells. Moreover, the $\mathrm{pH}$ inside the sperm cells had no influence on this process. Furthermore, the channel was blocked by three toxins that have no effect on the Slo3 potassium channels in mice, but are known to block a type of potassium channel known as Slo1. Mannowetz et al. then used a technique called Western blotting to confirm the presence of Slo1 potassium channels in the tails of human sperm cells.

Mannowetz et al. also showed that the Slo1 potassium channel can be blocked by the female hormone progesterone. This is important because blocking the potassium channels causes the calcium ion channels in the cells to open fully, and the resulting influx of calcium ions triggers a process called sperm hyperactivation that makes it possible for the sperm cell to fertilize the egg. By clearly showing the fundamental differences between human sperm cells and mouse sperm cells, this work stresses the need to exercise caution in using mice as a model of male fertility in humans. DOI: 10.7554/eLife.01009.002

a large cytosolic $\mathrm{C}$-terminus with two intracellular regulators of $\mathrm{K}^{+}$conductance (RCK), both of which contain high affinity $\mathrm{Ca}^{2+}$ binding sites (Jiang et al., 2001; Yuan et al., 2010). These structural elements give Slo1 channels the ability to sense changes in both voltage and intracellular $\mathrm{Ca}^{2+}$ concentrations (Marty, 1981; Pallotta et al., 1981; Barrett et al., 1982; Latorre et al., 1982; Schreiber et al., 1999). Due to their large single-channel conductance of 60-270 pS, Slo1 channels are also known as big potassium (BK) or maxi K channels (Atkinson et al., 1991; Kaczorowski et al., 1996; Salkoff et al., 2006). Slo3 channels, on the other hand, lack the $\mathrm{Ca}^{2+}$ bowl (Schreiber et al., 1999; Xia et al., 2004), but are sensitive to intracellular alkalinization (Schreiber et al., 1998; Zhang et al., 2006a, 2006b; Navarro et al., 2007). The pore-forming a subunits of Slo channels are associated with auxiliary $\beta$ - and $y$-subunits (Behrens et al., 2000; Brenner et al., 2000; Uebele et al., 2000; Yan and Aldrich, 2010, 2012; Yang et al., 2011), which interact with the S0 segment of the a subunit. Several studies demonstrate that the association with different subunits impacts channel pharmacological and gating properties. In addition, splice variants of the Slo1 mRNA contribute to the functional diversity of BK channels (Fodor and Aldrich, 2009; Johnson et al., 2011). Apart from responding to different stimuli, Slo1 and Slo3 channels are distributed discretely within the body as shown in numerous animal studies. Slo1 is detectable in excitable tissues, such as in hippocampus (Hicks and Marrion, 1998), smooth muscle cells (Knaus et al., 1994a, 1994b) and adrenal chromaffin cells (Solaro and Lingle, 1992), whereas Slo3 transcripts are exclusively expressed in male germ cells (Schreiber et al., 1998). Male Slo $1^{-/-}$animals are able to produce offspring when paired with $\mathrm{Slo}^{+/+}$females. However, the litter size was normal only in $10 \%$ of the matings (Meredith et alo, 2004). Abolishing the Slo3 gene results in more dramatic changes in testicular spermatozoa, such as morphological abnormalities after capacitation, reduced progressive motility, impaired acrosome reaction, and membrane depolarization during capacitation (Schreiber et alo, 1998; Santi et al., 2010; Zeng et al., 2011). These data indicate that Slo channels are essential for male fertility in mice, which makes them possible candidates for being the major $\mathrm{K}^{+}$channel of human sperm.

The goal of our work was to resolve the identity of the major $\mathrm{K}^{+}$channel in human ejaculated spermatozoa. By applying the patch-clamp technique to ejaculated and epididymal human sperm cells, we found that human $\mathrm{K}^{+}$currents are insensitive to intracellular alkalinization but are dependent 
on intracellular $\left[\mathrm{Ca}^{2+}\right]$. We furthermore demonstrate that the human sperm potassium (hKSper) current is inhibited by three known Slo1 channel inhibitors: charybdotoxin (Anderson et al., 1988; MacKinnon and Miller, 1988), iberiotoxin (Galvez et al., 1990; Candia et al., 1992; Giangiacomo et al., 1992) and paxilline (Knaus et al., 1994c; Sanchez and McManus, 1996; Zhou et al., 2010), as well as by the micromolar concentrations of progesterone. Taking together our electrophysiological, biochemical, and immunocytochemistry data, we conclude that the Slo1 protein constitutes a major potassium channel of human spermatozoa. Therefore, the molecular identity of human KSper is distinct from that of murine KSper, which is represented by the Slo3 protein.

\section{Results}

\section{hKSper currents originate from the sperm flagellum}

The flagellar $\mathrm{pH}$-dependent $\mathrm{Ca}^{2+}$ channel CatSper is indispensable for male fertility. However, to gain its full activity several events must be met: intracellular alkalinization, presence of progesterone and membrane depolarization (Ren et al., 2001; Kirichok et al., 2006; Lishko and Kirichok, 2010; Lishko et al., 2011; Strunker et al., 2011). Since $\mathrm{K}^{+}$channels are involved in the regulation of membrane potential, we hypothesized that the human KSper current $\left(I_{K S p e r}\right)$ also originates from the sperm tail to support CatSper activity. To address this question, we recorded from both whole sperm cells and isolated sperm flagella (Figure 1). To isolate $I_{\text {KSper }}$ from $I_{\text {Catsper }}$ we recorded $\mathrm{K}^{+}$currents in a potassium methanesulfonate-based solution in the presence of $0.1-1 \mathrm{mM}$ extracellular $\mathrm{Ca}^{2+}$. When divalent cations are absent from the extracellular solution, so called divalent free (DVF) condition, CatSper is able to conduct monovalent ions, such as $\mathrm{K}^{+}$. However, in the presence of 0.1-1 mM external $\mathrm{Ca}^{2+}$, $I_{\text {Catsper }}$ is effectively blocked (Kirichok et al., 2006; Lishko et al., 2011; Smith et al., 2013), thus leading to pure $\mathrm{K}^{+}$conductance through $\mathrm{K}^{+}$channels. As shown in Figure $1 \mathrm{~A}, \mathrm{~B}, \mathrm{~K}^{+}$currents elicited under DVF conditions were approximately four times larger than the current recorded in the presence of $1 \mathrm{mM}$ $\mathrm{Ca}^{2+}$. The larger potassium currents (gray bars) represent a mixture of the $\mathrm{K}^{+}$efflux through CatSper

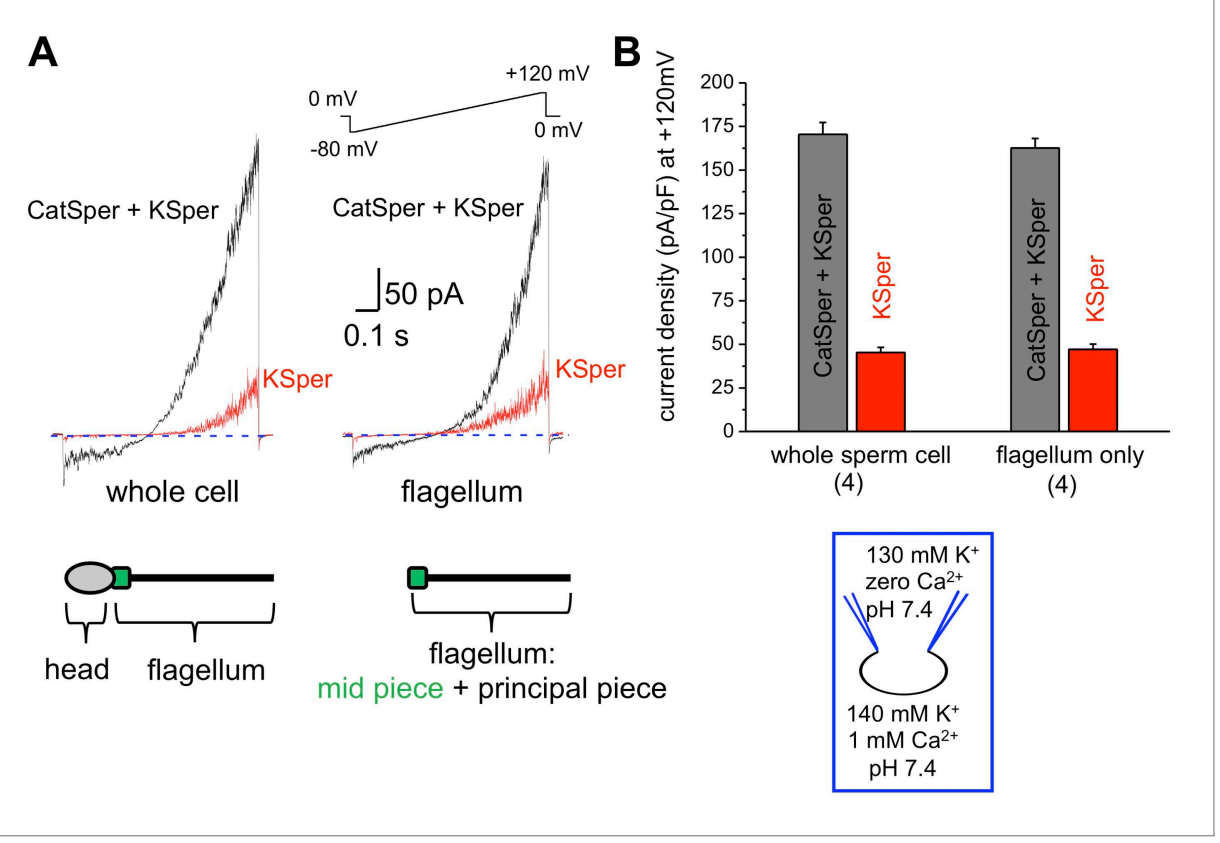

Figure 1. hKSper currents originate from the sperm tail. (A) $I_{\text {KSper }}$ was recorded in response to a voltage ramp as shown. Shown are representative traces from whole spermatozoon (left panel; recordings are from the same cell) and sperm tail (right panel; recordings are from the same flagellum). Black traces represent currents in divalent free conditions, which allow $\mathrm{K}^{+}$current through CatSper. Red traces show true $I_{K S p e r}$. Latter was recorded in the presence of $1 \mathrm{mM}$ extracellular $\mathrm{Ca}^{2+}$, which inhibits monovalent currents through CatSper. (B) Current densities were obtained at $+120 \mathrm{mV}$ and presented as mean \pm SEM. (n), number of experiments. Four different sperm cells (or four different sperm flagella) of two different human donors were used.

DOI: 10.7554/eLife.01009.003 
and KSper while only KSper current remains in the presence of external calcium (red bars). Similar amplitudes of KSper currents recorded from whole sperm cells or sperm flagella indicate that $I_{K S p e r}$ originate primarily from the sperm flagellum, in the same manner as does $I_{\text {Catsper }}$ (Figure 1B; Lishko et al., 2011).

\section{hKSper currents are insensitive to intracellular alkalinization}

Sperm intracellular alkalinization was shown to be essential for murine KSper (Slo3) activation (Navarro et al., 2007; Santi et al., 2010; Zeng et al., 2011). Recently, recombinant human Slo3 co-expressed with a $\mathrm{Y}$-subunit was also shown to exhibit pH-dependency (Leonetti et al., 2012). However, its pHsensitivity was shifted toward a more acidic $\mathrm{pH}$ range than that of mouse Slo3. Therefore, we decided to test whether human $\mathrm{KSper}$ exhibits the same $\mathrm{pH}$ sensitivity and recorded $\mathrm{K}^{+}$currents from human spermatozoa under conditions when intracellular $\mathrm{pH}\left(\mathrm{pH}_{\mathrm{i}}\right)$ was held either at $\mathrm{pH} 7.4$ or 5.5 , and external $\mathrm{pH}$ kept at 7.4. To evoke intracellular alkalinization, $10 \mathrm{mM}$ of $\mathrm{NH}_{4} \mathrm{Cl}$ was added to the external (bath) solution, which is a standard technique to effectively and quickly raise an intracellular $\mathrm{pH}$ (Babcock et al., 1983; Kirichok et al., 2006; Navarro et alo, 2007). In the experiments with a $\mathrm{pH}_{\mathrm{i}}$ of 5.5, $1 \mathrm{mM}$ of $\mathrm{Zn}^{2+}$ was added to the bath solution to inhibit sperm voltage-gated proton channel (Hv1) activity (Lishko et al., 2010). As shown in Figure 2A, human $I_{K s p e r}$ remained unaffected by intracellular alkalinization at both $\mathrm{pH}_{\mathrm{i}} 7.4$ (upper left panel) and $\mathrm{pH}_{\mathrm{i}} 5.5$ (lower left panel). However, $\mathrm{K}^{+}$currents were greatly potentiated by intracellular alkalinization in the absence of divalent cations (Figure 2A,B, right panels), which was primarily due to the activation of $\mathrm{pH}$-dependent $\mathrm{K}^{+}$efflux through $\mathrm{CatSper}$ channels. Note that in DVF conditions, control currents were larger than control KSper currents, due to the efflux of potassium ions through both KSper and CatSper channels. Intracellular alkalinization up-regulates CatSper channel activity, therefore increasing the potassium efflux through it, while KSper currents remain unchanged.

To exclude that components of the seminal plasma may alter human sperm $\mathrm{K}^{+}$channel behavior with regard to $\mathrm{pH}$ sensitivity, we also recorded $\mathrm{K}^{+}$currents from human epididymal spermatozoa from

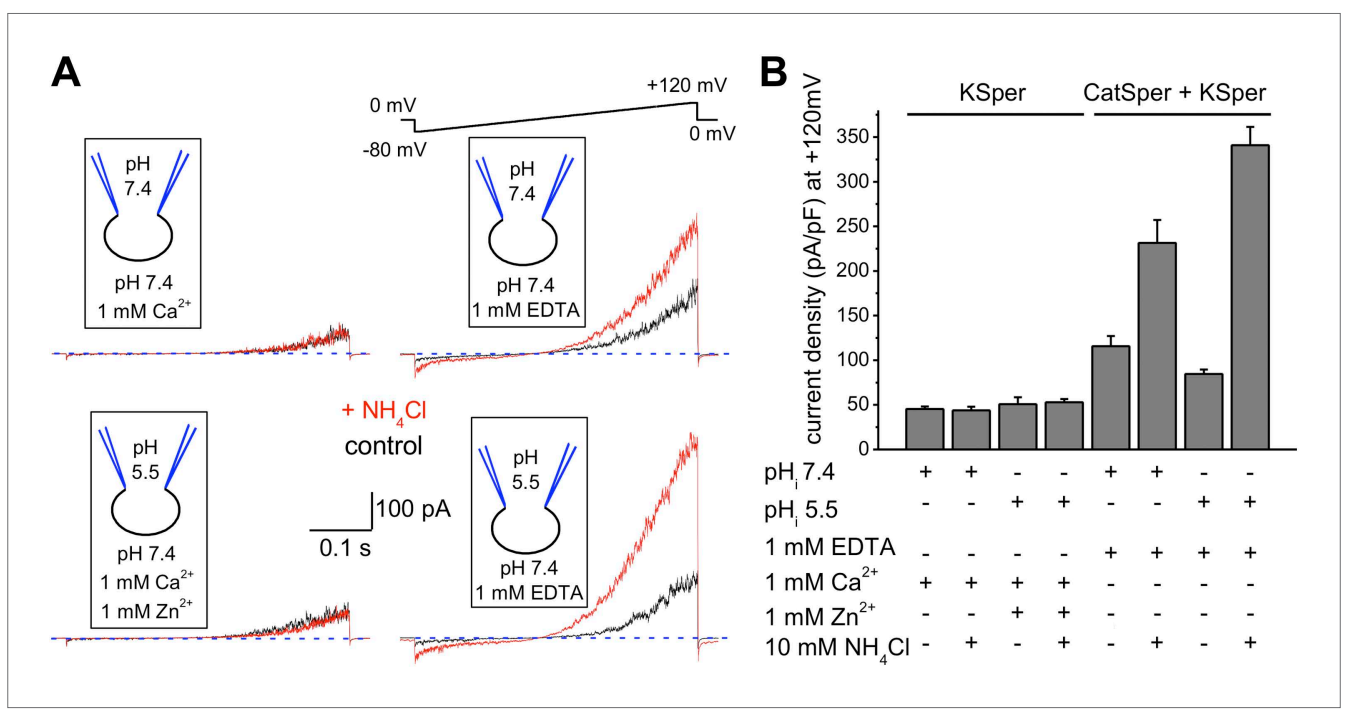

Figure 2. hKSper currents are insensitive to intracellular alkalinization. (A) Representative KSper currents were recorded from sperm cells in response to voltage ramps as shown. Recordings were done with various $\mathrm{pH}_{\mathrm{i}}$ as indicated. The bath solution containing $1 \mathrm{mM} \mathrm{Ca}^{2+}$ was used to inhibit $\mathrm{K}^{+}$current through CatSper (left panels). Right panels show traces in divalent free conditions, which allow $\mathrm{K}^{+}$current through CatSper. Intracellular alkalinization was evoked by addition of $10 \mathrm{mM} \mathrm{NH}_{4} \mathrm{Cl}$ to the bath (red traces). A weak intracellular buffer (5 $\mathrm{mM}$ of HEPES or MES) allowed instantaneous $\mathrm{pH}$ changes. $\mathrm{Zn}^{2+}$ was used to block $\mathrm{H}^{+}$currents via $\mathrm{Hv} 1$ at acidic intracellular $\mathrm{pH}$. The upper panels and the lower panels are recordings from two different sperm cells. (B) KSper and CatSper/ KSper current densities (CDs) recorded from sperm cells as shown in (A). At $\mathrm{pH}_{\mathrm{i}} 7.4 \mathrm{KSper}$ CDs were: $45 \pm 3 \mathrm{pA} / \mathrm{pF}$ (control) and $44 \pm 4 \mathrm{pA} / \mathrm{pF}$ (plus $\mathrm{NH}_{4} \mathrm{Cl}$ ). These values were similar at $\mathrm{pH}_{\mathrm{i}}$ 5.5: $\mathrm{CDs}$ were: $51 \pm 8 \mathrm{pA} / \mathrm{pF}$ (control) and $53 \pm 4 \mathrm{pA} / \mathrm{pF}$ (plus $\mathrm{NH}_{4} \mathrm{Cl}$ ). However, under DVF conditions that permit $\mathrm{K}^{+}$efflux through $\mathrm{CatSper} \mathrm{CDs}$ at $\mathrm{pH}_{\mathrm{i}} 7.4$ were: $116 \pm 11 \mathrm{pA} / \mathrm{pF}$ (control) and $231 \pm 26 \mathrm{pA} / \mathrm{pF}$ (plus $\mathrm{NH}_{4} \mathrm{Cl}$ ). At pH 5.5, CDs were: $85 \pm 5 \mathrm{pA} / \mathrm{pF}$ (control) and $341 \pm 21 \mathrm{pA} / \mathrm{pF}$ (plus $\mathrm{NH}_{4} \mathrm{Cl}$ ). Shown are CDs acquired at $+120 \mathrm{mV}$ and presented as mean $\pm \mathrm{SEM} ; \mathrm{n}=4-6$ independent experiments with cells from four different human donors.

DOI: 10.7554/eLife.01009.004 
a fertile patient undergoing vasectomy reversal. As shown in Figure $3, I_{K S p e r}$ did not change upon intracellular alkalinization. This indicates that the lack of hKSper $\mathrm{pH}$-sensitivity is not due to the effect of seminal plasma, but rather it is an intrinsic property of the human sperm potassium channel. This particular feature of human KSper differentiates it from mouse KSper and suggests that the molecular identities of the channels are different.

\section{hKSper is activated by intracellular calcium}

As mentioned earlier, the $\mathrm{pH}$-dependent mouse KSper channel is encoded by the Slo3 gene, while other members of the Slo family, such as Slo1 are not $\mathrm{pH}$-dependent, but rather $\mathrm{Ca}^{2+}$-dependent. To determine if intracellular calcium affects human $I_{K S p e r}$ we recorded $\mathrm{K}^{+}$currents under different intracellular free $\mathrm{Ca}^{2+}$ concentrations: $0,0.1$ or $50 \mu \mathrm{M}$ (Figure 4) with $0.1 \mathrm{mM} \mathrm{Ca}^{2+}$ in the bath solution. As illustrated in Figure $4 A, B$, the outward $I_{K S p e r}$ was slightly increased with $\left[\mathrm{Ca}^{2+}\right]_{i}=0.1 \mu \mathrm{M}$ compared to the control (zero calcium). Under these conditions, $I_{\text {KSper }}$ exhibited outward rectification. However, with a $\left[\mathrm{Ca}^{2+}\right]$ $=50 \mu \mathrm{M}$, not only was the outward current potentiated twofold, but an inward potassium current was also present. Interestingly, intracellular calcium also notably decreased the activation time for human KSper (Figure 4A, lower panel). However, the quantitative measurements of activation time constant in the presence of calcium were hindered by a fast channel kinetics that overlapped with capacitance artifacts.

Regulation by $\mathrm{Ca}^{2+}$ is a hallmark behavior of Slo1, but not Slo3 channels. Our results indicate that intracellular $\mathrm{Ca}^{2+}$, and not $\mathrm{pH}$, is a driving force for the opening of the human KSper channel and suggest that the molecular identity of hKSper might be the Slo1 protein rather than Slo3.

\section{hKSper is sensitive to Slo1 channel blockers charybdotoxin, iberiotoxin, and paxilline}

To verify the molecular identity of human KSper, we applied three of the known Slo1 channel blockers to the bath solution: charybdotoxin (ChTX) (Anderson et alo, 1988; MacKinnon and Miller, 1988), iberiotoxin (IbTX) (Galvez et al., 1990; Candia et al., 1992; Giangiacomo et al., 1992), and paxil-

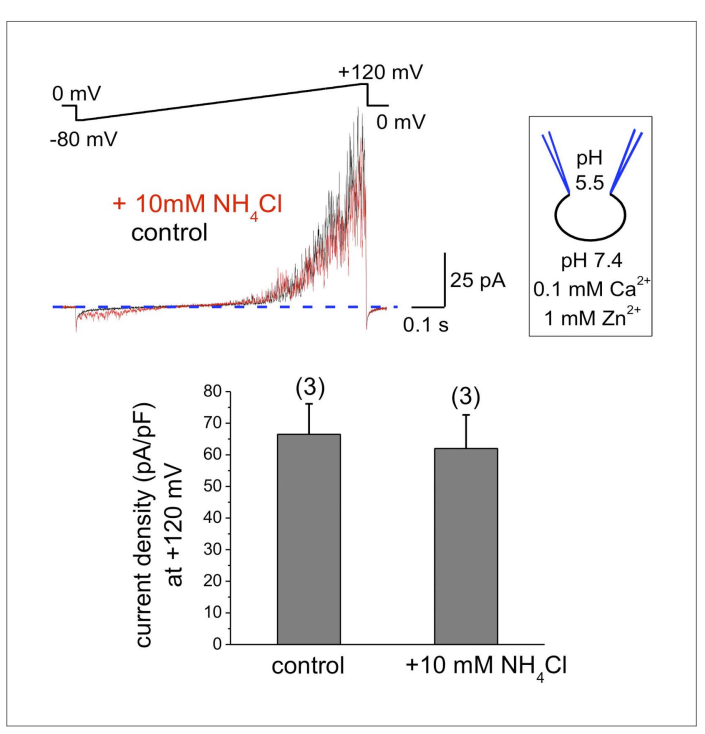

Figure 3. hKSper currents from human epididymal spermatozoa are insensitive to intracellular alkalinization. The upper panel shows representative $I_{\text {KSper }}$ traces recorded from human epididymal spermatozoa (whole sperm cell) in the control (black) and in the presence of $10 \mathrm{mM} \mathrm{NH}_{4} \mathrm{Cl}$ (red). The lower panel presents mean currents acquired at $+120 \mathrm{mV}$; $(\mathrm{n})$, number of experiments. $I_{\text {KSper }}$ did not change upon intracellular alkalinization with current densities averaging at $67 \pm 10 \mathrm{pA}$ (control) and $62 \pm 11 \mathrm{pA}$ (after addition of $10 \mathrm{mM} \mathrm{NH}_{4} \mathrm{Cl}$ ). Three epididymal spermatozoa were tested. DOI: 10.7554/eLife.01009.005 line (Knaus et al., 1994c; Sanchez and McManus, 1996; Zhou et al., 2010). Figure 5A,B shows a potent and reversible inhibition of human $I_{\text {KSper }}$ by $93 \%$ in the presence of $1 \mu \mathrm{M}$ ChTX. Human $\mathrm{K}^{+}$currents were also effectively blocked by both $100 \mathrm{nM} \mathrm{IbTX}$ (Figure 6A, B) and $100 \mathrm{nM}$ paxilline (Figure $7 A, B$ ) with $87 \%$ and $62 \%$ inhibition, respectively. To verify that this pharmacological profile was specific to Slo1, we also recorded $\mathrm{K}^{+}$ currents from mouse sperm, which express Slo3 (Schreiber et alı, 1998; Zhang et al., 2006a; Navarro et al., 2007; Santi et al., 2010; Zeng et al., 2011). It was previously reported that mouse Slo3 is insensitive to ChTX, IbTX, and paxilline (Tang et alo, 2010), and indeed Figures 5C,D, $6 C, D$, and $7 C, D$ demonstrate that mouse $K^{+}$currents remained unaffected upon stimulation with 1 HM ChTX, 100 nM IbTX, or 500 nM paxilline. The fact that human, but not mouse, KSper is sensitive to Slo1-specific channel blockers strongly suggests that Slo1 forms the potassium channel in human sperm.

Mouse KSper appeared to have both notably larger current amplitudes and current densities (Figures 5-7). Mouse spermatozoa are twice larger than human sperm cells: human sperm capacitance is usually within $1 \mathrm{pF}$, while the capacitance of mouse sperm is about $2.5 \mathrm{pF}$ (Kirichok et al., 2006; Lishko et al., 2010, 2011). However, the fact that KSper current densities $(\mathrm{pA} / \mathrm{pF})$ are still 


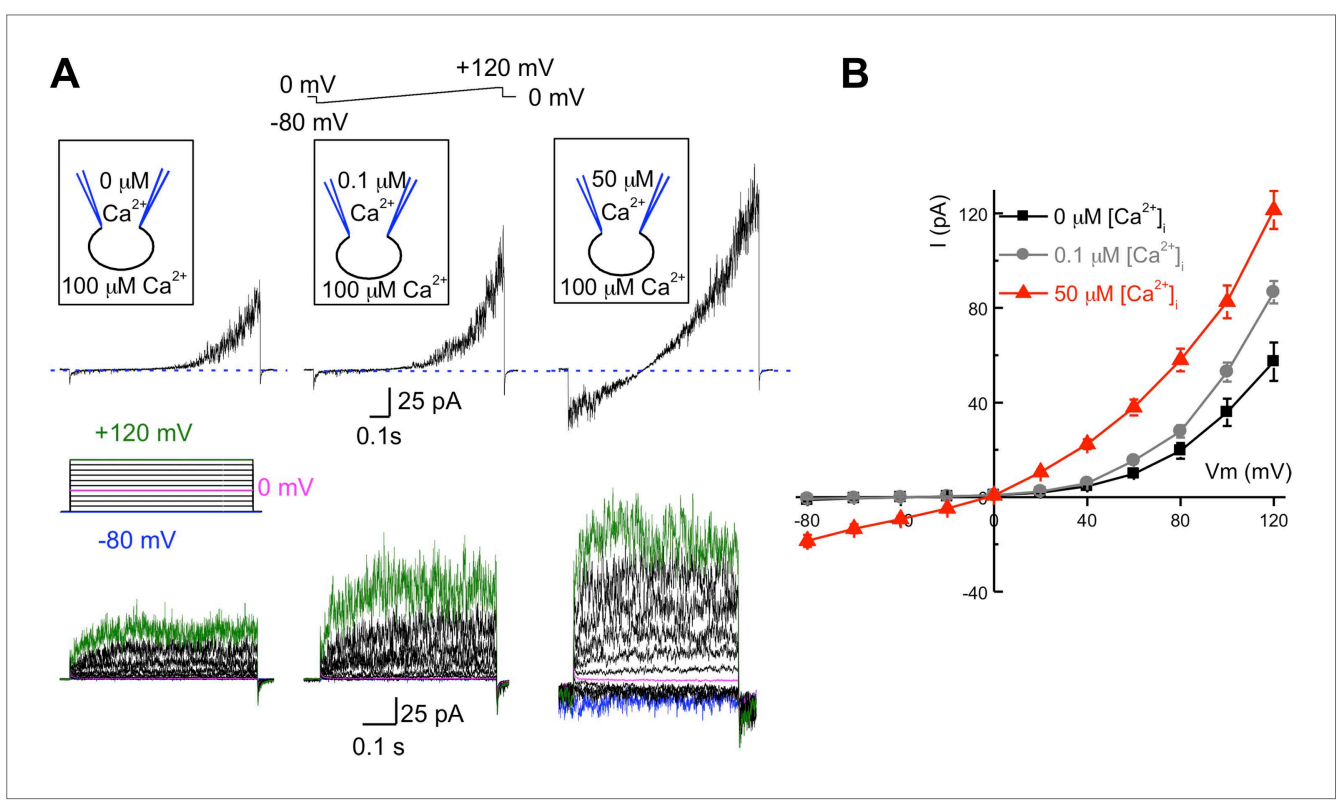

Figure 4. hKSper is activated by intracellular calcium. (A) Upper panels: representative $I_{\text {KSper }}$ recorded with various intracellular $\left[\mathrm{Ca}^{2+}\right]_{f r e e}$ as indicated, in response to a voltage ramp. Lower panels: corresponding representative $I_{K S p e r}$ elicited by a step protocol from a holding potential of $-80 \mathrm{mV}$ to $+120 \mathrm{mV}$ with $20 \mathrm{mV}$ increments. For clarity, traces at $-80 \mathrm{mV}, 0 \mathrm{mV}$, and $+120 \mathrm{mV}$ are labeled in blue, magenta, and green, respectively. Representative traces were obtained from three different sperm cells (upper and lower panels). (B) Current-voltage (I-V) relationship in response to $0 \mu \mathrm{M}$ (black), $0.1 \mu \mathrm{M}$ (gray), and $50 \mu \mathrm{M}$ (red) intracellular $\left[\mathrm{Ca}^{2+}\right]_{\text {free. }}$. At a membrane potential $(\mathrm{Vm})$ of $-80 \mathrm{mV}$, potassium currents were: $-1.2 \pm 0.5 \mathrm{pA}\left(\left[\mathrm{Ca}^{2+}\right]_{\mathrm{i}}=0\right),-0.8 \pm 0.2 \mathrm{pA}\left(\left[\mathrm{Ca}^{2+}\right]_{\mathrm{i}}=0.1 \mu \mathrm{M}\right)$, and $-18.5 \pm 2.6 \mathrm{pA}\left(\left[\mathrm{Ca}^{2+}\right]_{\mathrm{i}}=50\right.$ $\mu \mathrm{M})$. At Vm $=+120 \mathrm{mV}, I_{\text {KSpers }}$ were $57 \pm 8 \mathrm{pA}\left(\left[\mathrm{Ca}^{2+}\right]_{i}=0\right), 87 \pm 5 \mathrm{pA}\left(\left[\mathrm{Ca}^{2+}\right]_{i}=0.1 \mu \mathrm{M}\right)$, and $122 \pm 8 \mathrm{pA}\left(\left[\mathrm{Ca}^{2+}\right]_{i}=50\right.$ $\mu \mathrm{M})$. Data are shown as means $\pm \mathrm{SEM} ; \mathrm{n}=6-11$ independent experiments with cells from six different donors. Data are from whole sperm cells.

DOI: 10.7554/eLife.01009.006

larger in mouse sperm than in human spermatozoa indicates the potential differences in KSper expression and distribution along the sperm flagella.

\section{hKSper is blocked by progesterone}

We and others previously have shown that the sperm-specific calcium channel CatSper is activated by progesterone (Lishko et al., 2011; Strunker et al., 2011). Progesterone (P) shifts CatSper activation to more physiological, hyperpolarized, membrane potentials (Lishko et al., 2011). To test whether progesterone has any effect onto hKSper, we recorded $I_{\text {KSper }}$ in the presence of different progesterone concentrations in the bath solution. Figure $\mathbf{8 A}, \mathbf{C}$ shows that hKSper outward currents were blocked by progesterone in a dose-dependent manner. We have determined that progesterone's half-maximum inhibitory concentration ( $\left.\mathrm{IC}_{50}\right)$ for hKSper is $7.5 \pm 1.3 \mu \mathrm{M}$ (Figure 8B). Moreover, mouse Slo3 turned out to be insensitive to $10 \mu \mathrm{M}$ of progesterone (Figure 9), which is above the $\mathrm{IC}_{50}$ for human $\mathrm{KSper}$. Since potassium channels are well known to regulate the membrane potential (Navarro et al., 2007), it is likely that the inhibition of human KSper by $\mathrm{P}$ will produce membrane depolarization and create favorable conditions for opening of CatSper. CatSper activation, in turn, will result in an elevation of intracellular $\left[\mathrm{Ca}^{2+}\right]$ and trigger hyperactivated motility. To test this hypothesis we selectively blocked human KSper by adding $100 \mathrm{nM}$ ChTX to high saline (HS) bath solution in which sperm cells are usually kept, and recorded any changes in sperm motility. As evident from Video 1 sperm motility was symmetrical in the absence of the Slo1 inhibitor (ChTX). However, incubation in $100 \mathrm{nM}$ ChTX for 25 min resulted in sperm cells exhibiting an asymmetrical motility pattern similar to hyperactivation (Video 2). The normal, symmetrical motility was resumed after a prolonged washout (data not shown).

\section{The Slo1 protein present in human spermatozoa}

To confirm that the Slo1 protein is actually present in human spermatozoa, we performed immunostaining with anti-Slo1 specific antibodies. Figure 10A demonstrates that the antibody selectively stained the 


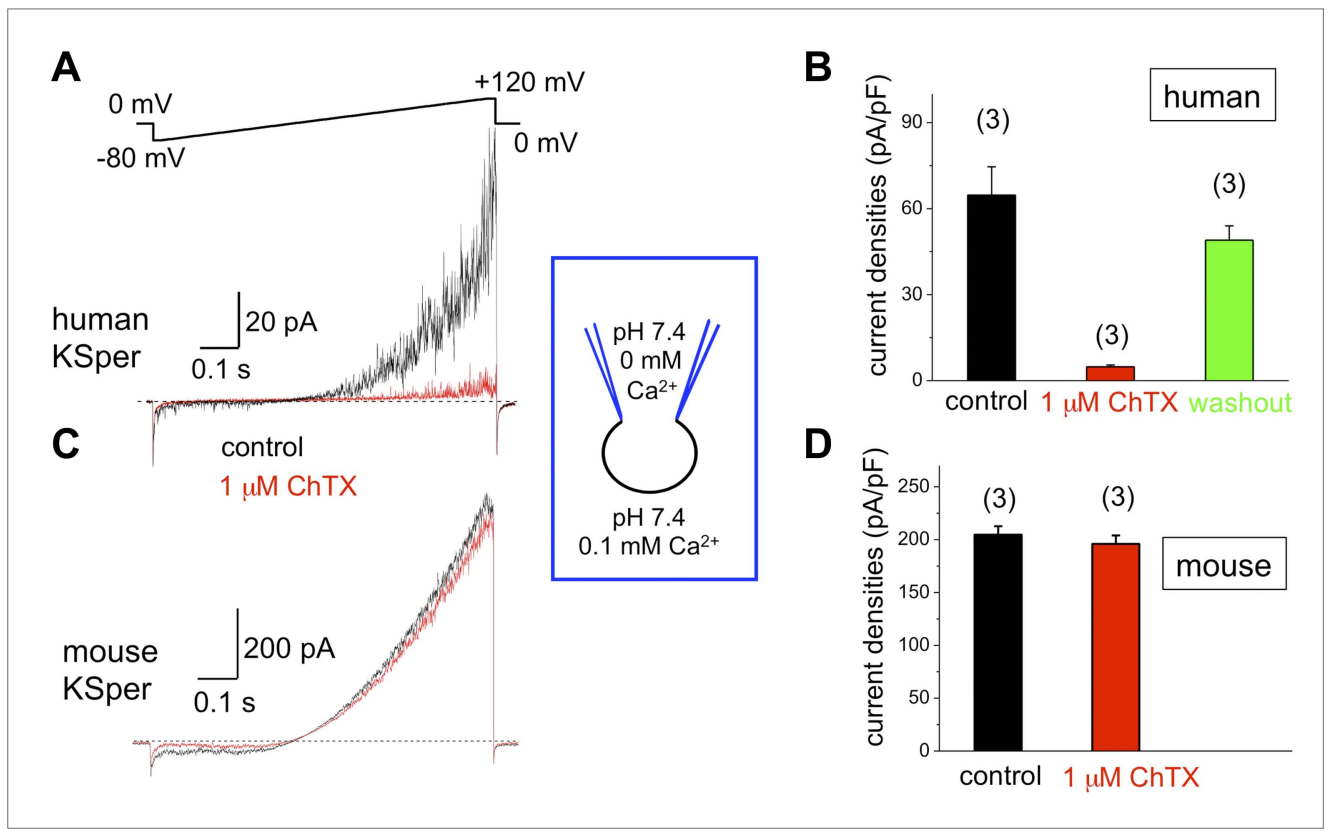

Figure 5. Human, but not mouse KSper is sensitive to the Slo1 channel blocker charybdotoxin (ChTX). (A) Representative human $I_{K S p e r}$ traces under control conditions (black) and in the presence of $1 \mu \mathrm{M}$ ChTX (red) elicited in response to the given voltage ramp. (B) Mean current densities (CDs) \pm SEM calculated at $+120 \mathrm{mV}$. CDs (human) were: $65 \pm 10 \mathrm{pA} / \mathrm{pF}$ (control), $5 \pm 1 \mathrm{pA} / \mathrm{pF}$ (ChTX), and $49 \pm 5 \mathrm{pA} / \mathrm{pF}$ (washout). (C) Representative mouse $I_{\text {KSper }}$ traces under control conditions (black) and in the presence of $1 \mu \mathrm{M}$ ChTX (red) elicited in response to the voltage ramp as shown in (A). (D) CDs (mouse) were: $205 \pm 8 \mathrm{pA} / \mathrm{pF}$ (control) vs $196 \pm 8 \mathrm{pA} / \mathrm{pF}$ (ChTX). (n), number of experiments. Three human and three mouse sperm cells were used.

DOI: 10.7554/eLife.01009.007

principal piece of the sperm flagellum, the same compartment where other sperm ion channels, such as Hv1 and CatSper, reside. The head and the flagellar midpiece region showed no signals (Figure 10A, middle and left panel). Furthermore, the presence of the Slo1 protein was confirmed by Western blotting (Figure 10B). Immunoreactive bands in the range of 110-130 kDa were detectable in human spermatozoa and in mouse brain, which served as the positive control.

We also tested the presence of Slo1 transcripts in human sperm cells. Indeed, both Slo1 a (kcnma1) and Slo1 $\beta 3$ (kcnmb3) transcripts were amplified from the total RNA isolated from human ejaculated sperm (Figure 11). Interestingly, Slo1 was shown to have a decreased sensitivity to ChTX in the complex with different auxiliary subunits (Xia et al., 1999). For example, the presence of the $\beta 3$ subunit in the Slo1 complex requires micromolar, but not nanomolar concentrations of ChTX to completely inhibit channel activity (Xia et al., 1999). Indeed, the $\beta 3$ subunit of Slo1 was shown to be expressed in testis (Uebele et al., 2000), and we also found transcripts of $\beta 3$ ( $k \mathrm{cnmb3}$ ) from sperm RNA (Figure 11, right panel). Therefore, a reduced sensitivity of human KSper to ChTX (nearly complete inhibition of activity was achieved only with $1 \mu \mathrm{M}$ (hTX) is likely due to the presence of the $\beta 3$ auxiliary subunit in human sperm.

\section{Discussion}

Potassium channels are indispensable for sperm physiology and are essential for membrane hyperpolarization upon sperm capacitation-the final sperm maturation in the female reproductive tract. Capacitation is also associated with intracellular alkalinization, which, in turn, has been shown to activate the calcium channel CatSper in human spermatozoa and the potassium channel KSper in murine sperm (Zeng et al., 1995; Arnoult et al., 1996; Kirichok et al., 2006; Navarro et al., 2007; Lishko et al., 2011). In mouse sperm, $\mathrm{K}^{+}$currents originate mainly from the Slo3 channel, which is alkalinization-activated, calcium-insensitive potassium channel (Schreiber et al., 1998; Zhang et al., 2006a, 2006b; Navarro et al., 2007; Santi et al., 2010; Yang et al., 2011; Zeng et al., 2011). The currents we recorded from human sperm, however, show very different properties. According to our data, KSper currents 


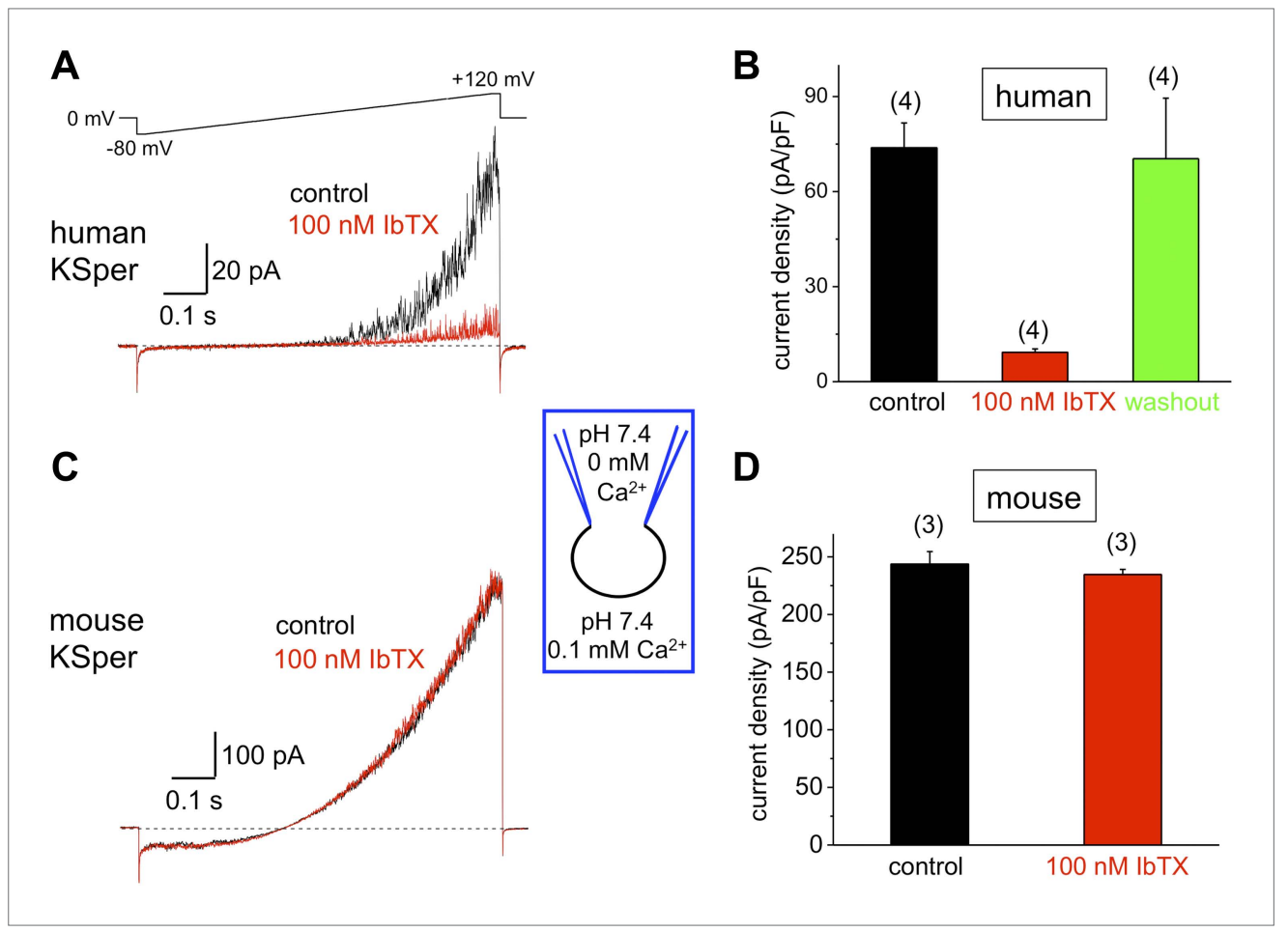

Figure 6. Human, but not mouse KSper is sensitive to the Slo1 channel blocker iberiotoxin (IbTX). (A) Representative human $I_{\text {KSper }}$ traces under control conditions (black) and in the presence of $100 \mathrm{nM} \mathrm{lbTX} \mathrm{(red)} \mathrm{elicited} \mathrm{in} \mathrm{response} \mathrm{to}$ the shown voltage ramp. (B) Mean current densities (CDs) \pm SEM calculated at $+120 \mathrm{mV}$. CDs (human) were $74 \pm 8$ $\mathrm{pA} / \mathrm{pF}$ (control), $9 \pm 1 \mathrm{pA} / \mathrm{pF}$ (IbTX), and $70 \pm 19 \mathrm{pA} / \mathrm{pF}$ (washout). (C) Representative mouse $I_{\text {KSper }}$ traces under control conditions (black) and in the presence of $100 \mathrm{nM} \mathrm{IbTX} \mathrm{(red)} \mathrm{elicited} \mathrm{in} \mathrm{response} \mathrm{to} \mathrm{the} \mathrm{voltage} \mathrm{ramp} \mathrm{as} \mathrm{in} \mathrm{(A).}$ (D) CDs (mouse) were $244 \pm 11 \mathrm{pA} / \mathrm{pF}$ (control) and $235 \pm 4 \mathrm{pA} / \mathrm{pF}$ (IbTX). (n), number of experiments. Four human and three mouse sperm cells were used.

DOI: 10.7554/eLife.01009.008

recorded either from human epididymal or ejaculated spermatozoa were alkalization-independent producing the same current amplitudes at $\mathrm{pH}_{\mathrm{i}}=5.5$ and 7.4. However, we found that human KSper instead is sensitive to intracellular calcium.

Capacitation also results in the elevation of intracellular calcium (Visconti et al., 2002). The C-terminus of Slo1 potassium channel possesses RCK domains with high-affinity $\mathrm{Ca}^{2+}$ binding sites (Moss et al., 1996; Schreiber and Salkoff, 1997; Jiang et al., 2001; Yuan et al., 2010). This raises the possibility that Slo1 may represent human KSper. Associated y- (leucine-rich repeat-containing proteins, LRRCs) and $\beta$-subunits further modulate channel behavior in response to calcium. Subunits Y1 (LRRC26), Y2 (LRRC52), Y3 (LRRC55), and Y4 (LRRC38) produce a shift towards more hyperpolarized membrane potentials, even in the absence of intracellular calcium and transcripts for all four subunits are detectable in human testis (Yan and Aldrich, 2010, 2012; Yang et al., 2011). So far, four $\beta$ subunits ( $\beta 1-4)$ have been identified and are expressed in a tissue-specific manner. Subunits $\beta 2-4$ are mainly expressed in brain and neurons, $\beta 3$ is also detectable in testis, whereas the $\beta 1$ subunit is preferentially found in smooth muscle cells (Knaus et al., 1994b; Behrens et al., 2000; Brenner et al., 2000; Uebele et al., 2000). hSlo1 activation time is reduced when the a subunit is co-expressed with $\beta 3$ (Brenner et al., 2000). Inward currents with increased concentrations of calcium $(10,60$, and $300 \mu \mathrm{M})$ occur when the $\alpha$-subunit is expressed alone and are potentiated in the presence of subunit $\beta 1$ and $\beta 3$ (Xia et al., 2000). Keeping the $\left[\mathrm{Ca}^{2+}\right]_{\mathrm{i}}=10 \mu \mathrm{M}$, an inward current becomes apparent when Slo1 $\alpha$ is co-expressed with $\beta 1$ and $\beta 4$, whereas $\beta 2$ and $\beta 3$ show no effect (Brenner et al., 2000; Lippiat et al., 2003). These data can be explained by the presence of $\beta 3$ splice variants ( $\beta 3 a-d)$ arising from four different exons with each of them encoding for an alternative $\mathrm{N}$ terminus (Zeng et al., 2008). One study so far showed that $\beta 3 b, \beta 3 c$, and $\beta 3 d$ transcripts are present in human testis, with $\beta 3 d$ showing the greatest expression (Uebele et al., 2000). It is possible that $I_{K S p e r}$ of human spermatozoa originates from Slo1 $\alpha$-subunits, 


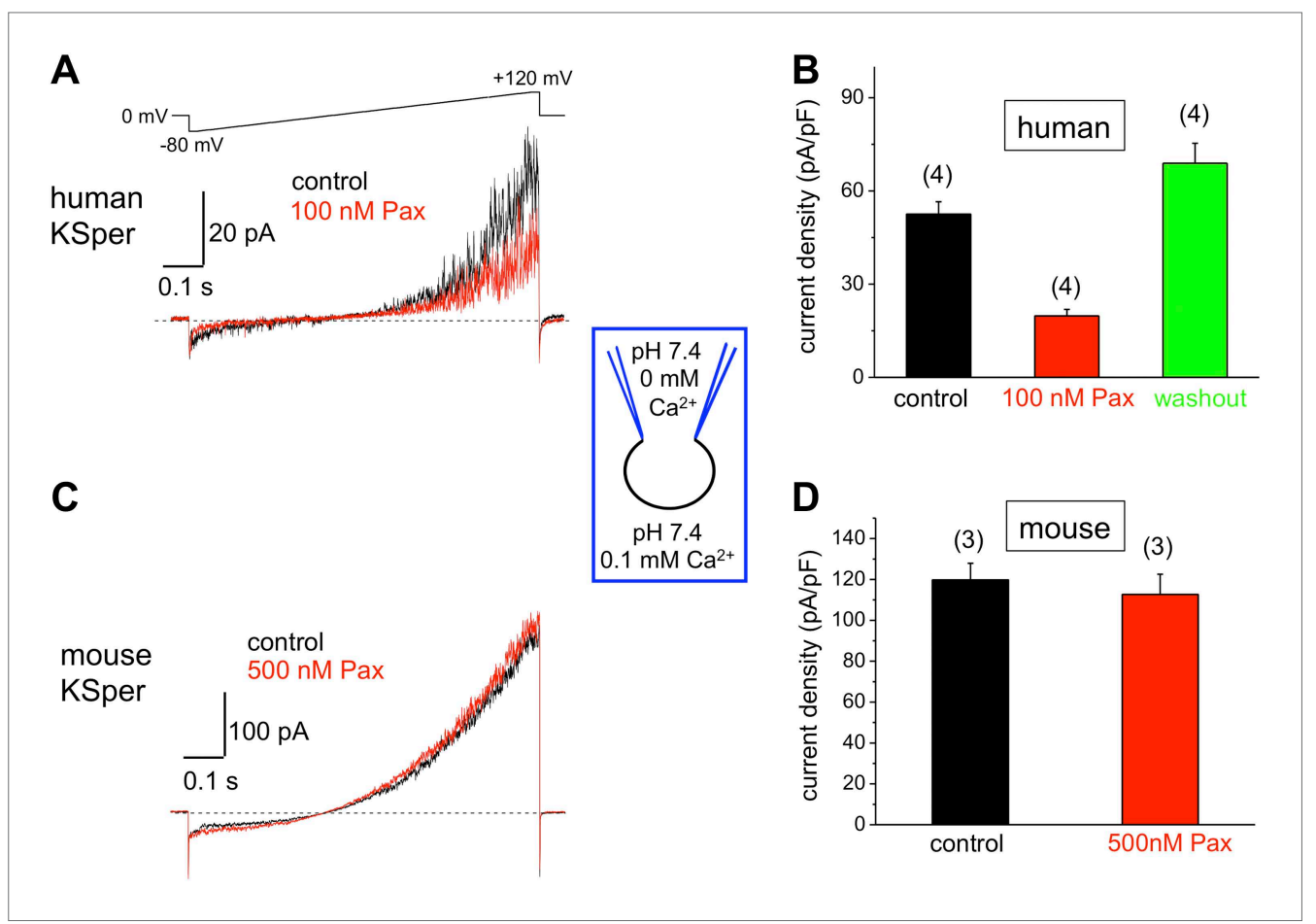

Figure 7. Human, but not mouse KSper is sensitive to the Slo1 channel blocker paxilline (Pax). (A) Representative human $I_{K S p e r}$ traces under control conditions and in the presence of paxilline elicited in response to the indicated voltage ramp. (B) Mean current densities (CDs) \pm SEM calculated at $+120 \mathrm{mV}$. Cells from three donors were used. CDs (human) were: $53 \pm 4$ pA (control), $20 \pm 2$ pA (100 nM paxilline), and $69 \pm 6$ pA (washout). (C) Representative mouse $I_{\text {KSper }}$ traces under control conditions and in the presence of paxilline elicited in response to the voltage ramp as in (A). (D) CDs (mouse) were: $119 \pm 5 \mathrm{pA} / \mathrm{pF}$ (control) and $113 \pm 10 \mathrm{pA} / \mathrm{pF}$ (500 nM paxilline). (n), number of experiments. Four human and three mouse sperm cells were used.

DOI: 10.7554/eLife.01009.009

which are in the complex with $\gamma, \beta$, or even both auxiliary subunits. Indeed, according to our data, $\beta 3$ transcripts are present in the RNA pool isolated from mature ejaculated human sperm cells. Moreover, our data show that elevated intracellular calcium strongly potentiates outward current and results in the appearance of an inward current. These hKSper properties (calcium sensitivity and pH-insensitivity) favor the idea that Slo1 represents the potassium channel in human spermatozoa.

Slo1 channels are potently blocked by the scorpion peptide toxins charybdotoxin (ChTX) (Miller et al., 1985; Anderson et al., 1988; MacKinnon and Miller, 1988) and iberiotoxin (IbTX) (Galvez et al., 1990; Candia et al., 1992; Giangiacomo et al., 1992). However, there is evidence that all four $\beta$-subunits can confer resistance to these toxins. It has been reported that IbTX effectively blocks recombinant hSloa with an $\mathrm{IC}_{50}$ of $33 \mathrm{nM}$, but IbTX inhibition of recombinant hSloa in a complex with $\beta 1$ raises $I C_{50}$ to $371 \mathrm{nM}$ (Lippiat et al., 2003). Also, subunit $\beta 2$ greatly reduces the sensitivity of the $\alpha$ subunit to ChTX (IC $C_{50}=1 \mathrm{nM}$ vs $\left.58 \mathrm{nM}\right)$ (Wallner et al., 1999). Another study revealed that $20 \mathrm{nM}$ ChTX was sufficient to block recombinant hSloa, whereas $100 \mathrm{nM}$ of toxin was required to inhibit hSloa $+\beta 1$. Moreover, even $100 \mathrm{nM}$ of ChTX was insufficient to effectively block hSloa $+\beta 3$ (Xia et alo, 1999). Furthermore, slower blocking kinetics for ChTX and IbTX have been shown in hSloo $+\beta 4$ constructs (Meera et al., 2000). Northern blot analyses demonstrate that mRNA for subunits $\beta 3$ and $\beta 4$ is detectable in human testis (Brenner et al., 2000), and it has been shown that the resistance to $\mathrm{IbTX}$ and ChTX is determined by the large extracellular loop of the $\beta 4$ subunit (Meera et al., 2000). Since we observed different blocking kinetics with $\mathrm{ChTX}$ ( $93 \%$ reduction with $1 \mu \mathrm{M} \mathrm{ChTX)}$ and IbTX ( $87 \%$ reduction with $100 \mathrm{nM} \mathrm{IbTX),} \mathrm{it} \mathrm{seems} \mathrm{likely} \mathrm{that} \mathrm{in} \mathrm{human} \mathrm{sperm,} \mathrm{the} \mathrm{Slo1} \mathrm{channel} \mathrm{is} \mathrm{associated}$ with $\beta$ subunits that modulate channel behavior in response to these toxins.

Paxilline, a fungal indole alkaloid, has also been shown to inhibit Slo1 channels (Knaus et al., 1994c; Sanchez and McManus, 1996). Interestingly, Slo3 is paxilline insensitive, and recently it has been 


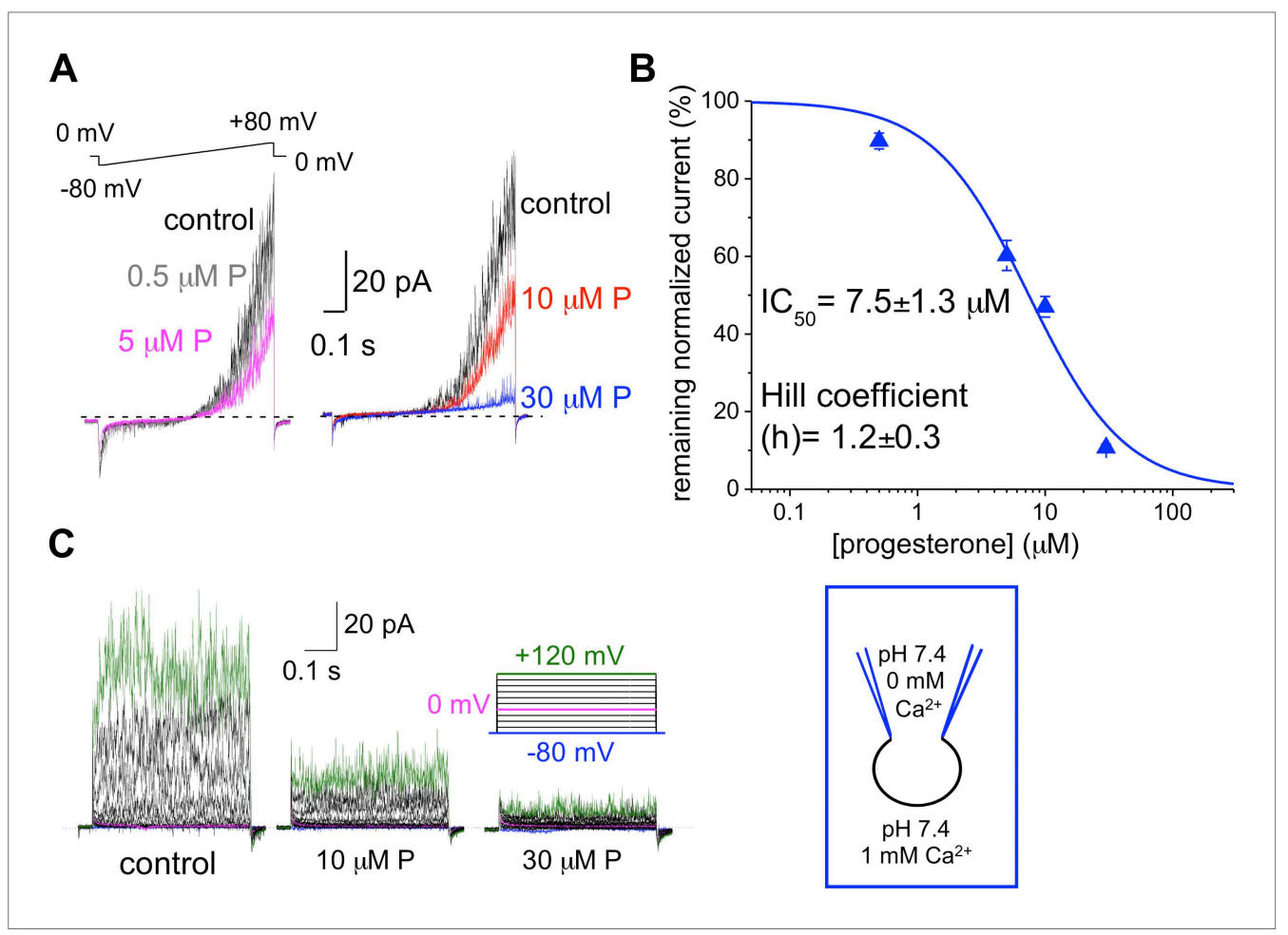

Figure 8. hKSper is blocked dose-dependently by progesterone (P). (A) Representative $I_{\text {KSper }}$ recordings from two sperm cells (left and right panel) in response to the given voltage ramp protocol under control conditions (black), $0.5 \mu \mathrm{M}$ P (gray), $5 \mu \mathrm{M}$ P (magenta), $10 \mu \mathrm{M}$ P (red), and $30 \mu \mathrm{M} \mathrm{P}$ (blue). (B) Dose-dependent inhibition of human $I_{\text {KSper }}$ by progesterone. Human $I_{\text {KSper }}$ amplitudes were acquired at $+80 \mathrm{mV}$ at the end of the voltage ramps, as shown in (A). Current amplitudes in the presence of indicated progesterone concentrations were normalized onto control amplitudes (in the absence of progesterone). Remaining $I_{\text {KSper }}$ in the presence of $0.5 \mu \mathrm{M}, 5 \mu \mathrm{M}, 10 \mu \mathrm{M}$ and $30 \mu \mathrm{M}$ of P was: $90 \pm 2 \%, 60 \pm 4 \%, 47 \pm 3 \%$ and $11 \pm 1 \%$, respectively. Data were fitted with the Hill equation. Data shown are means \pm SEM of 4-10 sperm cells from three different donors. (C) Representative $I_{\text {KSper }}$ traces elicited by the given voltage step protocol of the control (left panel) and in the presence of $10 \mu \mathrm{M} \mathrm{P}$ (middle panel) and $30 \mu \mathrm{M} \mathrm{P}$ (right panel). Recordings are from the same cell as in (A).

DOI: 10.7554/eLife.01009.010

demonstrated that paxilline binds to a glycine residue at position 311 within the S6 segment of the a-subunit (Zhou et al., 2010). This effect is independent of auxiliary subunits. However, the same study elucidated other factors within the Slo channel structure, which seem to be important for paxilline block. First, the turret region could determine the effectiveness of paxilline block. The turret is the extracellular loop between S5 and the pore domain, which contains more residues in Slo channels as compared to other $\mathrm{K}^{+}$channels (Carvacho et al., 2008; Giangiacomo et al., 2008; Latorre et al., 2010). Replacing the first half of the mSlo1 pore loop with the corresponding mSlo3 sequence leads to a five times greater paxilline inhibition and increases inhibition and washout rates (Zhou et al., 2010). A second source for altered abilities of paxilline inhibition is the pore loop region in the S6 segment, which differs in 10 residues between Slo1 and Slo3. When we applied $100 \mathrm{nM}$ paxilline to human spermatozoa, only $62 \%$ of hKSper reduction was observed, whereas even a fivefold higher concentration did not affect currents recorded from mouse sperm. From these data, we conclude that in human spermatozoa, either the turret region or the S6 segment of BK channels show properties that do not allow a complete block of the $\mathrm{K}^{+}$currents by paxilline.

We and others previously have shown that progesterone is a potent non-genomic activator of CatSper with an $\mathrm{EC}_{50}$ of $8 \mathrm{nM}$ (Lishko et al., 2011; Strunker et al., 2011). But as apparent from this study, progesterone also blocks human $\mathrm{KSper}$ with an $\mathrm{IC}_{50}$ of around $8 \mu \mathrm{M}$. Moreover, murine KSper is not affected by $10 \mu \mathrm{M}$ progesterone. Together, the data from steroid and toxin treatment indicate that pharmacological properties of human and mouse KSper channels are quite different. 


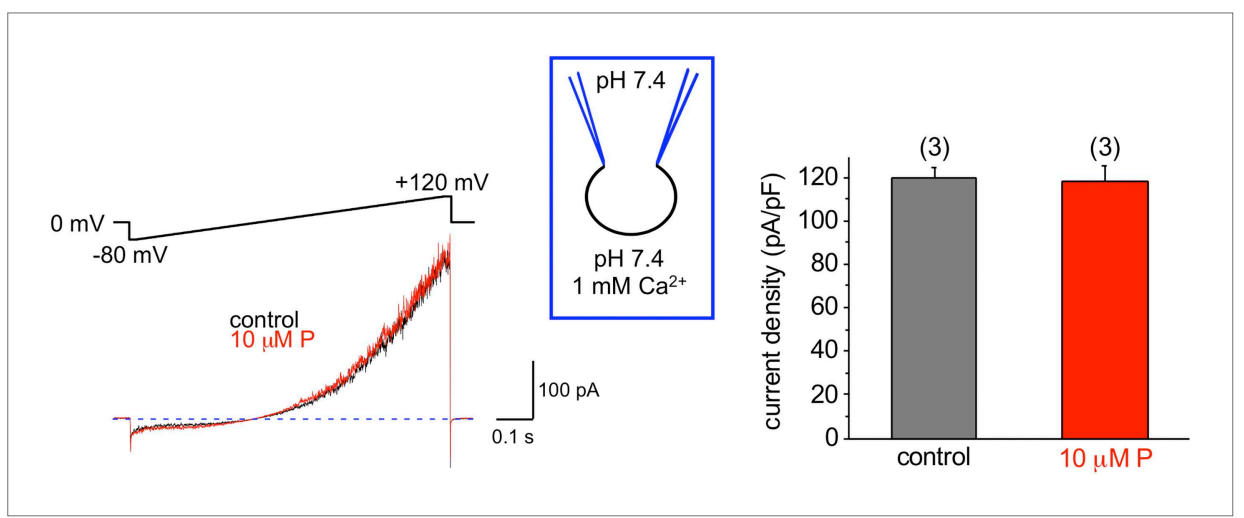

Figure 9. Mouse KSper is insensitive to progesterone (P). The left panel shows representative traces of mouse $I_{K S p e r}$ of the control (black) and in the presence of $10 \mu \mathrm{M} P(\mathrm{red})$. The right panel shows current densities (CDs) acquired at $+120 \mathrm{mV}$ presented as mean \pm SEM. CDs were: $119 \pm 5 \mathrm{pA} / \mathrm{pF}$ (control) and $118 \pm 8 \mathrm{pA} / \mathrm{pF}(10 \mu \mathrm{M} \mathrm{P})$. (n), number of experiments. Three sperm cells were used.

DOI: 10.7554/eLife.01009.011

In conclusion, we show that human $I_{K S p e r}$ originated from the sperm flagellum, the same compartment where also CatSper and Hv1 channels reside (Lishko et al., 2010, 2011). Human KSper is a $\mathrm{pH}$-independent, calcium-sensitive potassium channel sensitive to selective Slo1 inhibitors, such as charybdotoxin, iberiotoxin and paxilline, and is inhibited by micromolar concentrations of progesterone. Apart from its localization in sperm flagella, mouse KSper lacks all earlier-mentioned properties. Taken together, these results indicate that the human sperm potassium channel comprises the Slo1 protein and not Slo3. In addition, we propose the following model: the functional proximity of KSper to other sperm

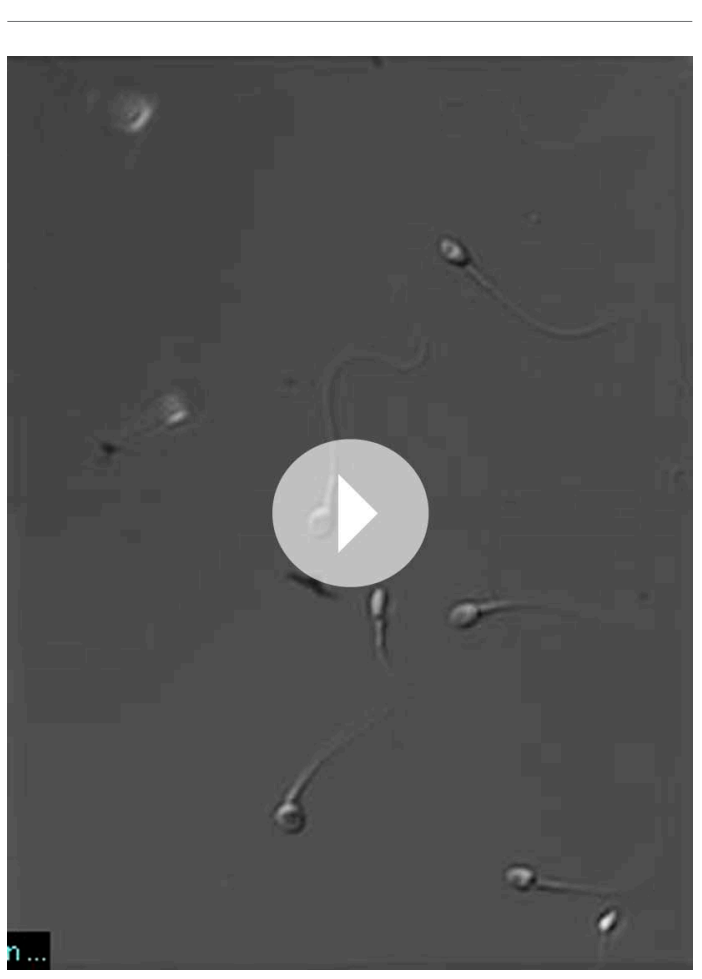

Video 1. Inhibition of hKSper induces a hyperactivationlike motility pattern. Normal motility of human spermatozoa in the control HS solution. Scale bar is $5 \mathrm{~mm}$. Recording was slowed down five times. DOI: 10.7554/eLife.01009.012 ion channels helps temporally coordinate their actions in a concerted manner during capacitation (Figure 12). In the uterus and the Fallopian tube, intracellular alkalinization is evoked by $\mathrm{Hv} 1$, thus activating CatSper channels. However, CatSper will not be fully active, as hKSper channels function as feedback regulators in response to calcium influx, thus retaining the membrane potential in a hyperpolarized state. In close proximity to the oocyte however, sperm encounter high concentrations of progesterone, which, in turn, will block hKSper, leading to membrane depolarization opening CatSper channels, which will become fully potentiated by the presence of progesterone. These events will lead to elevated levels of intracellular calcium in sperm, thereby initiating calcium-dependent processes such as hyperactivity and the acrosome reaction making the fertilization event possible.

\section{Materials and methods}

\section{Human sperm cells}

A total of 19 healthy fertile volunteers aged 21-38 years were recruited for this study. The study was conducted with approval of the Committee on Human Research at the University of California, Berkeley (protocol 10-01747, IRB reliance \#151), and University of California, San 


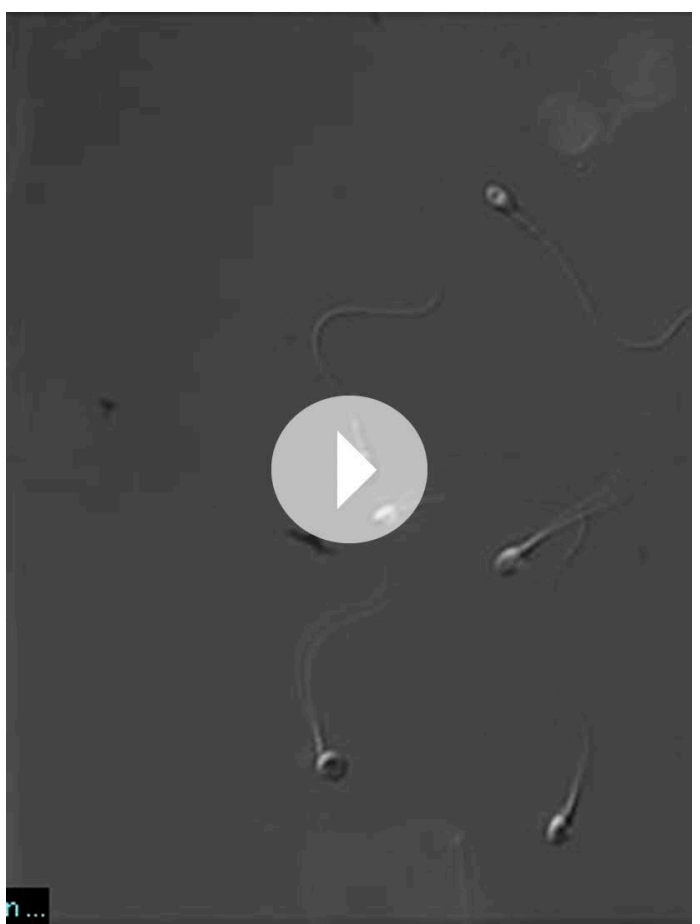

Video 2. Inhibition of hKSper induces a hyperactivationlike motility pattern. Motility of human spermatozoa is altered after incubation in HS solution, which contained $100 \mathrm{nM}$ of charybdotoxin (ChTX). Scale bar is $5 \mathrm{~mm}$. Recording was slowed down five times. DOI: 10.7554/eLife.01009.013
Francisco (protocol 10-04868). Informed consent was obtained from all participants. Ejaculates were obtained by masturbation and spermatozoa were purified following the swim-up protocol as previously described (Lishko et al., 2011). Men with proven fertility who were undergoing sperm retrieval procedures or a vasectomy reversal in the UCSF Center for Reproductive Health were also included in this study. As part of the ongoing IRBapproved LIFE (Lifestyle, Fertility, and Evaluation) study, men who agreed to participate donated portions of surgical specimens. All men enrolled in the present study had a documented history of prior paternity and had undergone a vasectomy in the past. As part of routine clinical care, these men elected to undergo a sperm retrieval procedure (microscopic epididymal sperm aspiration, MESA, or percutaneous epididymal sperm aspiration, PESA) combined with in vitro fertilization (IVF) or a vasectomy reversal. An aliquot of epididymal fluid was used for the present study with patient consent.

\section{Animals}

Male C57BL/6 mice were purchased from Harlan Laboratories (Livermore, CA) and were kept in the Animal Facility of the University of California, Berkeley. All experiments were performed in strict accordance with the NIH Guidelines for Animal Research and approved by UC Berkeley Animal Care and Use Committee, the approved protocol MAUP \#R352-012. Animals were killed by $\mathrm{CO}_{2}$ asphyxiation and cervical dislocation, and sperm were collected as described previously (Wennemuth et al., 2003).

\section{Reagents}

Progesterone was purchased from CalBiochem (EMD Millipore, Darmstadt, Germany), charybdotoxin and iberiotoxin from Tocris Bioscience (Bristol, UK), and all other compounds were obtained from Sigma (St. Louis, MO, USA).

\section{Electrophysiology}

Gigaohm seals were formed at the cytoplasmic droplet (Cooper, 2011) of highly motile cells or separated flagella in standard high saline (HS) buffer containing (in $\mathrm{mM}$ ) $130 \mathrm{NaCl}, 20 \mathrm{HEPES}$, 10 lactic acid, 5 glucose, $5 \mathrm{KCl}, 2 \mathrm{CaCl}_{2}, 1 \mathrm{MgSO}_{4}$, 1 sodium pyruvate, $\mathrm{pH} 7.4$ adjusted with $\mathrm{NaOH}, 320$ $\mathrm{mOsm} / \mathrm{l}$ as reported in Lishko et al. $(2010,2013)$. Transition into whole-cell mode was achieved by applying voltage pulses $(499-611 \mathrm{mV}, 1 \mathrm{~ms})$ and simultaneous suction. Cells were stimulated every $5 \mathrm{~s}$, data were sampled at $10 \mathrm{kHz}$ and filtered at $1 \mathrm{kHz}$ and access resistance was $21-57 \mathrm{M} \Omega$. Pipettes

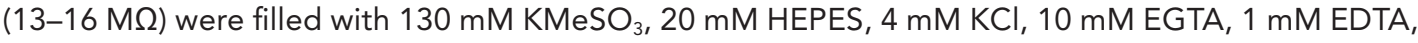
and pH 7.4 was adjusted with $\mathrm{KOH}, 330 \mathrm{mOsm} / \mathrm{l}$. In the experiments with $\mathrm{NH}_{4} \mathrm{Cl}$, pipette solutions were of similar composition, but contained just $5 \mathrm{mM}$ HEPES to allow efficient intracellular pH changes. The nominal free bath solution (NMF) consisted of (in mM) $140 \mathrm{KMeSO}_{3}, 20 \mathrm{HEPES}$, and pH 7.4 was adjusted with $\mathrm{KOH}, 320 \mathrm{mOsm} / \mathrm{l}$. To inhibit monovalent currents through CatSper channels (Smith et al., 2013), 0.1-1 $\mathrm{mM} \mathrm{Ca}^{2+}$ was added to the NMF solution, as indicated. To elicit potassium currents through CatSper, currents were recorded in a $\mathrm{K}^{+}-$based divalent free bath solution (K-DVF) containing (in $\mathrm{mM}$ ) $140 \mathrm{KMeSO}_{3}, 45 \mathrm{HEPES}, 1$ EDTA, 7.4 adjusted with $\mathrm{KOH}, 320 \mathrm{mOsm} / \mathrm{l}$. Inside (pipette) solutions with different concentrations of free $\mathrm{Ca}^{2+}$ contained (in mM) $130 \mathrm{KMeSO}_{3}, 20 \mathrm{HEPES}, 4 \mathrm{KCl}$ and 1 BAPTA, 1 EDTA, 1 EGTA (for $100 \mathrm{nM} \mathrm{Ca}^{2+}$ ) or $1 \mathrm{HEDTA}$ (for $50 \mu \mathrm{M} \mathrm{Ca}^{2+}$ ), respectively. $\mathrm{CaCl}_{2}$ was added according to WinMAXC32 version 2.51 (Chris Patton, Stanford University). Since changing of 


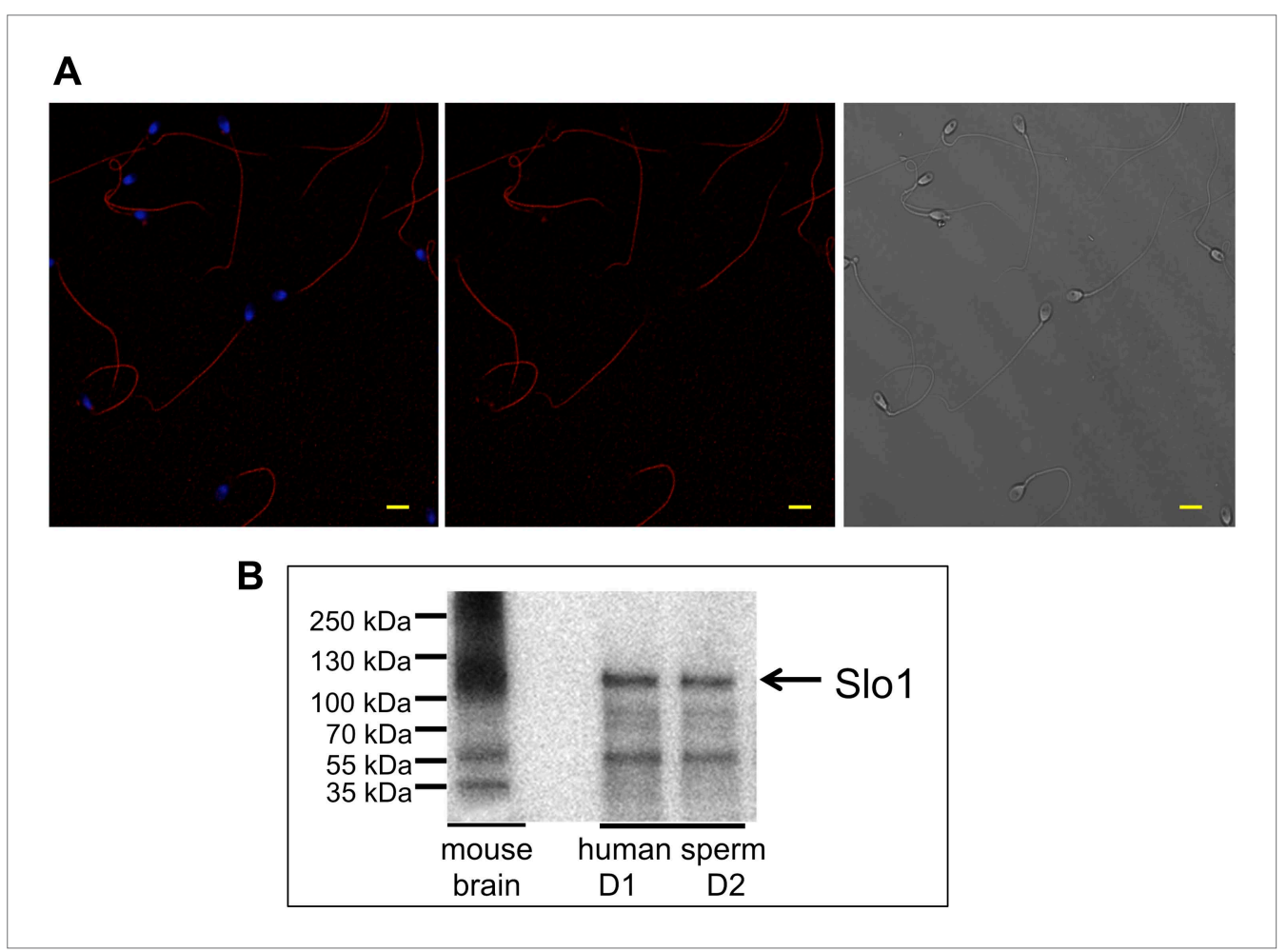

Figure 10. Slo1 protein is present in human spermatozoa. (A) Human sperm immunostaining with primary polyclonal anti-Slo1 antibodies and Cy3-conjugated secondary antibodies. Left and middle panels show Slo1 staining localized to the principal piece of human sperm flagellum. Left panel: nuclei are stained by DAPI. Right panel: DIC image of the same cells. Scale bar is $5 \mathrm{~mm}$. (B) Representative immunoblot of the mouse brain (positive control) and human spermatozoa from two different donors (donor 1 and donor 2: D1 and D2, respectively).

DOI: 10.7554/eLife.01009.014

the pipette solution cannot be easily done on one cell, the data obtained with different intracellular $\mathrm{pH}$ or different intracellular $\left[\mathrm{Ca}^{2+}\right]$ are a combination of recordings from multiple cells. However, since the changing of bath solution can be easily accomplished on the same cell, the experiments with different bath solutions (addition of EDTA, extracellular calcium, $\mathrm{NH}_{4} \mathrm{Cl}, \mathrm{ChTX}$, IbTX, Paxilline, progesterone, etc) were performed on the same sperm cell (flagellum): before and after addition of the above-mentioned compound. Data were analyzed with Clampfit 10.3 (Molecular Devices, Sunnyvale, CA, USA) and OriginPro 8.6 (OriginLab Corp., Northampton, MA, USA). Statistical data are presented

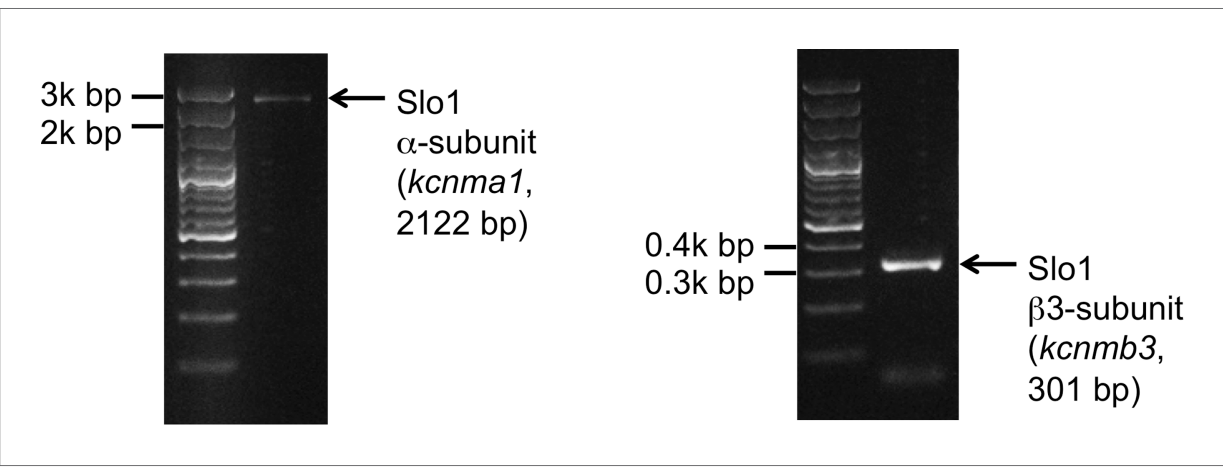

Figure 11. Slo1 transcripts are present in human spermatozoa. PCR bands of the portion of the translated region of kcnma1 (left panel; 1433-3554 bp, corresponding to the coding sequence of splice isoform1; UniProt \# Q12791), and of the translated region of kcnmb3 (right panel; 529-829 bp of the coding sequence of splice isoform 3d, Uniprot \# Q9NPA1). DOI: 10.7554/eLife.01009.015 


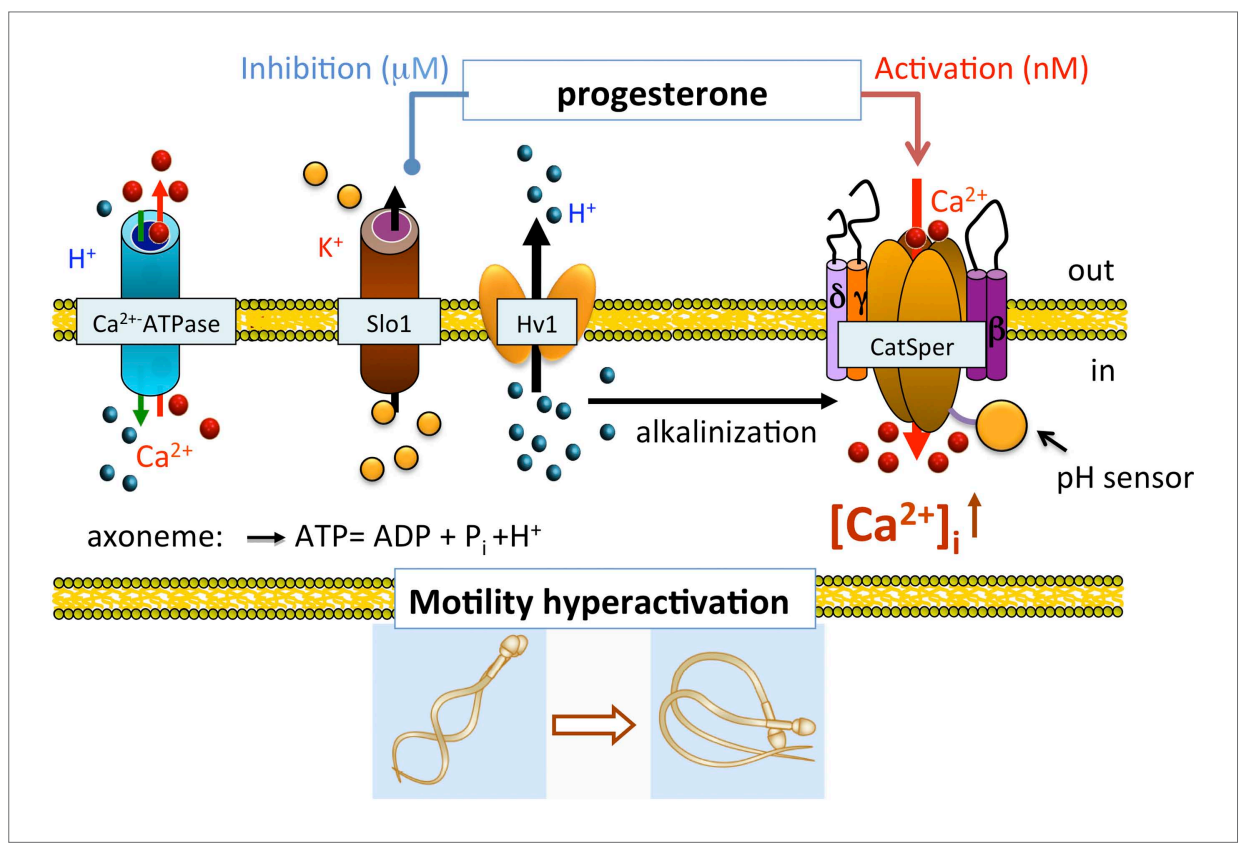

Figure 12. Role of human KSper (Slo1) in sperm physiology. In the uterus and fallopian tube, CatSper is partially activated due to the intracellular alkalinization evoked by proton extrusion through $\mathrm{Hv} 1$ and picomolar- to nanomolar progesterone (P) concentrations. However, to achieve full activation of CatSper, flagellar plasma membrane must be depolarized. This is achieved by the inhibition of sperm KSper, the channel responsible for membrane hyperpolarization. In close proximity to the oocyte, spermatozoa encounter micromolar concentrations of $\mathrm{P}$, which inhibit hKSper, resulting in membrane depolarization. These events allow full activation of CatSper, trigger sperm hyperactivation, allow spermatozoa to penetrate through the egg protective vestment, and make fertilization possible.

DOI: 10.7554/eLife.01009.016

as mean \pm standard error of the mean (SEM), and $n$ indicates number of experiments. All electrophysiology experiments were performed at $24^{\circ} \mathrm{C}$.

\section{Immunocytochemistry}

Cells were seeded onto cover slips in HS solution and allowed to adhere for 30 min at room temperature (RT). Cells were fixed with ice cold methanol for $1 \mathrm{~min}$, washed in PBS, and subsequently permeabilized with PBS/0.1\% Triton (PBS-T) with 5\% BSA for $1 \mathrm{hr}$ at room temperature. Incubation with the primary antibody (rabbit anti-Maxi K+ alpha, 1:100 in PBS-T and BSA, Thermo Scientific, \# PA1-923) was performed at $4^{\circ} \mathrm{C}$ overnight. Cells were then washed in PBS-T and incubated with Cy3 conjugated goat anti-rabbit IgG for $45 \mathrm{~min}$ at room temperature. After washing, the samples were mounted with ProLong Gold antifade reagent. Images were taken on a Zeiss LSM 710 microscope (Carl Zeiss Microscopy, Oberkochen, Germany) and processed with the Zeiss ZEN 2010B imaging software.

\section{Electrophoresis and immunoblotting}

Purified human spermatozoa were centrifuged and re-suspended in lysis buffer containing $0.1 \%$ SDS, $0.5 \%$ sodium deoxycholate, $50 \mathrm{mM}$ dithiothreitol (DTT), $20 \mathrm{mM}$ EDTA, 4 M urea and protease inhibitor cocktail (Roche). After sonication for $5 \mathrm{~min}$, the cell suspension was mixed 1:0.5 with water, then mixed 1:1 with sample buffer, and sonicated again for $5 \mathrm{~min} \beta$-mercaptoethanol (5\%) was added to each sample and after boiling $\left(5 \mathrm{~min}, 100^{\circ} \mathrm{C}\right)$ samples were transferred to a 4-12\% polyacryalamide gel and blotted on PVDF membranes. Membranes were fixed with methanol followed by blocking with $3 \%$ IgG-free BSA in PBS containing 0.1\% Tween (PBS-T) for $30 \mathrm{~min}$ at room temperature. Subsequently, membranes were incubated with $1 \mu \mathrm{g}$ of $\mathrm{mAb}$ anti-Slo1 (clone L6/60) (UC Davis/NIH NeuroMab Facility, Davis, CA, USA) overnight at $4^{\circ} \mathrm{C}$. After washing three times with PBS-T, the membranes were incubated with HRP-conjugated anti-mouse IgG (1:20,000 dilution) for $1 \mathrm{hr}$ at room temperature. Protein bands were detected by enhanced chemiluminescence on a Fluor Chem M imaging system (Protein Simple). 


\section{RNA extraction and RT-PCR}

Spermatozoa were purified by swim-up procedure and total donor-specific RNA was extracted from purified spermatozoa using a Qiagen RNeasy mini kit followed by cDNA synthesis with a Phusion RT-PCR kit (Finnzymes, MA, USA). The donor- specific translated regions of kcnma1 between 1433 $\mathrm{bp}$ and $3554 \mathrm{bp}$ (corresponding to the canonical coding sequence of Slo1 $\alpha$ isoform1; UniProt id Q12791) and kcnmb3 between 529 bp and 829 bp of the canonical coding sequence (Slo1 $\beta$ isoform 3d, Uniprot id Q9NPA1) were amplified using the following primers: 5'-ATGCCTCGAAT ATCATGAGAG-3' (kcnma1， forward), 5'-TATATTGGTTGATCTGGTTAGCC-3' (kcnma1，reverse); 5'-CTCGCCTAGGTTCTTCGATCACAAAAATGG-3' (kcnmb3, forward), and a reverse 5'-ATCGCTCG AGCTGCTCTTCCTTTGCTCCT-3' (kcnmb3, reverse). All PCRs were carried out for 40 cycles of replication and had annealing temperatures of $61^{\circ} \mathrm{C}$. The obtained PCR products were gel-purified and sequence-verified (Sequetech, Mountain View, CA, USA).

\section{Video recording of human sperm movement}

Purified spermatozoa were plated onto 5-mm coverslips in HS solution. Sperm movement was recorded within the first $3 \mathrm{hr}$ after sperm retrieval with a high speed GX-1 Memrecam camera (NAC Image Technology) attached to an Olympus IX71 microscope (Olympus Corp., Central Valley, PA, USA). The recording speed was 960 frames per second (fps), and videos were slowed down to playback at $200 \mathrm{fps}$ where indicated.

\section{Acknowledgements}

We thank Sam Coleman from the Molecular Imaging Center, UC Berkeley, for his help with the confocal images. We thank Dr Yuriy Kirichok from UCSF for the help and advice with the pilot experiments, and Dr Donner Babcock and Dr Melissa Miller for helpful suggestions. We are also very grateful to DO Nors for continuing invaluable contributions to this research. This work was supported by Winkler Family Foundation Fellowship and \#5-FY13-204 Basil O'Connor March of Dimes award to PVL.

\section{Additional information}

Funding

\begin{tabular}{lll} 
Funder & Grant reference number & Author \\
\hline Basil O'Connor March of Dimes & \#5-FY13-204 & Polina V Lishko \\
\hline Winkler Family Foundation & & Polina V Lishko \\
\hline $\begin{array}{l}\text { National Institute of Child Health } \\
\begin{array}{l}\text { and Human Development, National } \\
\text { Institutes of Health }\end{array}\end{array}$ & K12 & James F Smith \\
\hline
\end{tabular}

The funders had no role in study design, data collection and interpretation, or the decision to submit the work for publication.

\section{Author contributions}

NM, Helped design the experiments, performed most of the experiments, analyzed and interpreted data, and wrote the manuscript; NMN, Performed molecular biology experiments, analyzed and interpreted data, and helped write the manuscript; S-ASC, Performed immunocytochemistry experiments, analyzed the data, and helped revise the manuscript; JFS, Contacted patients, conducted surgeries and provided biopsy samples, discussed the results, and commented on the manuscript; PVL, Conceived the project, designed the experiments, performed pilot experiments, analyzed and interpreted data, and wrote the manuscript

\section{Ethics}

Human subjects: The study was conducted with approval of the Committee on Human Research at the University of California, Berkeley (protocol 10-01747, IRB reliance \#151), and University of California, San Francisco (protocol 10-04868). Informed consent was obtained from all participants. Men with proven fertility who were undergoing sperm retrieval procedures or a vasectomy reversal 
in the UCSF Center for Reproductive Health were included in this study. As part of the ongoing IRBapproved study (approval number 10-04868), men who agreed to participate donated portions of surgical specimens.

Animal experimentation: Male C57BL/6 mice were purchased from Harlan Laboratories (Livermore, CA) and were kept in the Animal Facility of the University of California, Berkeley. All experiments were performed in strict accordance with the NIH Guidelines for Animal Research and approved by UC Berkeley Animal Care and Use Committee, the approved protocol MAUP \#R352-012. Animals were killed by $\mathrm{CO}_{2}$ asphyxiation and cervical dislocation.

\section{References}

Adelman JP, Shen KZ, Kavanaugh MP, Warren RA, Wu YN, Lagrutta A, et al. 1992. Calcium-activated potassium channels expressed from cloned complementary DNAs. Neuron 9:209-16. doi: 10.1016/08966273(92)90160-F.

Anderson CS, MacKinnon R, Smith C, Miller C. 1988. Charybdotoxin block of single Ca2+-activated K+ channels. Effects of channel gating, voltage, and ionic strength. J Gen Physiol 91:317-33. doi: 10.1085/ jgp.91.3.317.

Arnoult C, Cardullo RA, Lemos JR, Florman HM. 1996. Activation of mouse sperm T-type Ca2+ channels by adhesion to the egg zona pellucida. Proc Natl Acad Sci USA 93:13004-9. doi: 10.1073/pnas.93.23.13004.

Atkinson NS, Robertson GA, Ganetzky B. 1991. A component of calcium-activated potassium channels encoded by the Drosophila slo locus. Science 253:551-5. doi: 10.1126/science.1857984.

Austin CR. 1952. The capacitation of the mammalian sperm. Nature 170:326. doi: 10.1038/170326a0.

Babcock DF, Rufo GA Jnr, Lardy HA. 1983. Potassium-dependent increases in cytosolic pH stimulate metabolism and motility of mammalian sperm. Proc Natl Acad Sci USA 80:1327-31. doi: 10.1073/pnas.80.5.1327.

Barrett JN, Magleby KL, Pallotta BS. 1982. Properties of single calcium-activated potassium channels in cultured rat muscle. J Physiol 331:211-30.

Behrens R, Nolting A, Reimann F, Schwarz M, Waldschutz R, Pongs O. 2000. hKCNMB3 and hKCNMB4, cloning and characterization of two members of the large-conductance calcium-activated potassium channel beta subunit family. FEBS Lett 474:99-106. doi: 10.1016/S0014-5793(00)01584-2.

Brenner R, Jegla TJ, Wickenden A, Liu Y, Aldrich RW. 2000. Cloning and functional characterization of novel large conductance calcium-activated potassium channel beta subunits, hKCNMB3 and hKCNMB4. J Biol Chem 275:6453-61. doi: 10.1074/jbc.275.9.6453.

Butler A, Tsunoda S, McCobb DP, Wei A, Salkoff L. 1993. mSlo, a complex mouse gene encoding "maxi" calcium-activated potassium channels. Science 261:221-4. doi: 10.1126/science.7687074.

Candia S, Garcia ML, Latorre R. 1992. Mode of action of iberiotoxin, a potent blocker of the large conductance $\mathrm{Ca}(2+)$-activated K+ channel. Biophys J 63:583-90. doi: 10.1016/S0006-3495(92)81630-2.

Carvacho I, Gonzalez W, Torres YP, Brauchi S, Alvarez O, Gonzalez-Nilo FD, et al. 2008. Intrinsic electrostatic potential in the BK channel pore: role in determining single channel conductance and block. J Gen Physiol 131:147-61. doi: 10.1085/jgp.200709862.

Chang MC. 1951. Fertilizing capacity of spermatozoa deposited into the fallopian tubes. Nature 168:697-8. doi: $10.1038 / 168697 b 0$.

Chen Y, Cann MJ, Litvin TN, lourgenko V, Sinclair ML, Levin LR, et al. 2000. Soluble adenylyl cyclase as an evolutionarily conserved bicarbonate sensor. Science 289:625-8. doi: 10.1126/science.289.5479.625.

Cooper TG. 2011. The epididymis, cytoplasmic droplets and male fertility. Asian J Androl 13:130-8. doi: 10.1038/ aja.2010.97.

Cui J, Aldrich RW. 2000. Allosteric linkage between voltage and $\mathrm{Ca}(2+)$-dependent activation of BK-type mslo1 $\mathrm{K}(+)$ channels. Biochemistry 39:15612-9. doi: 10.1021/bi001509+.

Demarco IA, Espinosa F, Edwards J, Sosnik J, De La Vega-Beltran JL, Hockensmith JW, et al. 2003. Involvement of a $\mathrm{Na}+/ H C O-3$ cotransporter in mouse sperm capacitation. J Biol Chem 278:7001-9. doi: 10.1074/jbc.M206284200.

Diaz L, Meera P, Amigo J, Stefani E, Alvarez O, Toro L, et al. 1998. Role of the S4 segment in a voltage-dependent calcium-sensitive potassium (hSlo) channel. J Biol Chem 273:32430-6. doi: 10.1074/jbc.273.49.32430.

Fodor AA, Aldrich RW. 2009. Convergent evolution of alternative splices at domain boundaries of the BK channel. Annu Rev Physiol 71:19-36. doi: 10.1146/annurev.physiol.010908.163124.

Galvez A, Gimenez-Gallego G, Reuben JP, Roy-Contancin L, Feigenbaum P, Kaczorowski GJ, et al. 1990. Purification and characterization of a unique, potent, peptidyl probe for the high conductance calcium-activated potassium channel from venom of the scorpion Buthus tamulus. J Biol Chem 265:11083-90.

Giangiacomo KM, Becker J, Garsky C, Schmalhofer W, Garcia ML, Mullmann TJ. 2008. Novel alpha-KTx sites in the BK channel and comparative sequence analysis reveal distinguishing features of the BK and KV channel outer pore. Cell Biochem Biophys 52:47-58. doi: 10.1007/s12013-008-9026-3.

Giangiacomo KM, Garcia ML, McManus OB. 1992. Mechanism of iberiotoxin block of the large-conductance calcium-activated potassium channel from bovine aortic smooth muscle. Biochemistry 31:6719-27. doi: 10.1021/bi00144a011.

Hicks GA, Marrion NV. 1998. Ca2+-dependent inactivation of large conductance Ca2+-activated K+ (BK) channels in rat hippocampal neurones produced by pore block from an associated particle. J Physio/ 508:721-34. doi: 10.1111/j.1469-7793.1998.721bp.x. 
Jiang Y, Pico A, Cadene M, Chait BT, MacKinnon R. 2001. Structure of the RCK domain from the E. coli K+ channel and demonstration of its presence in the human BK channel. Neuron 29:593-601. doi: 10.1016/ S0896-6273(01)00236-7.

Johnson BE, Glauser DA, Dan-Glauser ES, Halling DB, Aldrich RW, Goodman MB. 2011. Alternatively spliced domains interact to regulate BK potassium channel gating. Proc Natl Acad Sci USA 108:20784-9. doi: 10.1073/ pnas.1116795108.

Kaczorowski GJ, Knaus HG, Leonard RJ, McManus OB, Garcia ML. 1996. High-conductance calcium-activated potassium channels; structure, pharmacology, and function. J Bioenerg Biomembr 28:255-67. doi: 10.1007/ BF02110699.

Kirichok Y, Navarro B, Clapham DE. 2006. Whole-cell patch-clamp measurements of spermatozoa reveal an alkaline-activated Ca2+ channel. Nature 439:737-40. doi: 10.1038/nature04417.

Knaus HG, Folander K, Garcia-Calvo M, Garcia ML, Kaczorowski GJ, Smith M, et al. 1994a. Primary sequence and immunological characterization of beta-subunit of high conductance $\mathrm{Ca}(2+)$-activated $\mathrm{K}+$ channel from smooth muscle. J Biol Chem 269:17274-8.

Knaus HG, Garcia-Calvo M, Kaczorowski GJ, Garcia ML. 1994b. Subunit composition of the high conductance calcium-activated potassium channel from smooth muscle, a representative of the mSlo and slowpoke family of potassium channels. J Biol Chem 269:3921-4.

Knaus HG, McManus OB, Lee SH, Schmalhofer WA, Garcia-Calvo M, Helms LM, et al. 1994c. Tremorgenic indole alkaloids potently inhibit smooth muscle high-conductance calcium-activated potassium channels. Biochemistry 33:5819-28. doi: 10.1021/bi00185a021.

Latorre R, Morera FJ, Zaelzer C. 2010. Allosteric interactions and the modular nature of the voltage- and Ca2+activated (BK) channel. J Physio/ 588:3141-8. doi: 10.1113/jphysiol.2010.191999.

Latorre R, Vergara C, Hidalgo C. 1982. Reconstitution in planar lipid bilayers of a Ca2+-dependent K+ channel from transverse tubule membranes isolated from rabbit skeletal muscle. Proc Natl Acad Sci USA 79:805-9. doi: 10.1073/pnas.79.3.805.

Leonetti MD, Yuan P, Hsiung Y, Mackinnon R. 2012. Functional and structural analysis of the human SLO3 pH- and voltage-gated K+ channel. Proc Natl Acad Sci USA 109:19274-9. doi: 10.1073/ pnas.1215078109.

Lippiat JD, Standen NB, Harrow ID, Phillips SC, Davies NW. 2003. Properties of BK (Ca) channels formed by bicistronic expression of hSloalpha and beta1-4 subunits in HEK293 cells. J Membr Biol 192:141-8. doi: 10.1007/s00232-002-1070-0.

Lishko P, Clapham DE, Navarro B, Kirichok Y. 2013. Sperm patch-clamp. Methods Enzymol 525:59-83. doi: 10.1016/B978-0-12-397944-5.00004-3.

Lishko PV, Botchkina IL, Fedorenko A, Kirichok Y. 2010. Acid extrusion from human spermatozoa is mediated by flagellar voltage-gated proton channel. Cell 140:327-37. doi: 10.1016/j.cell.2009.12.053.

Lishko PV, Botchkina IL, Kirichok Y. 2011. Progesterone activates the principal Ca2+ channel of human sperm. Nature 471:387-91. doi: 10.1038/nature09767.

Lishko PV, Kirichok Y. 2010. The role of Hv1 and CatSper channels in sperm activation. J Physiol 588:4667-72. doi: 10.1113/jphysiol.2010.194142.

Lishko PV, Kirichok Y, Ren D, Navarro B, Chung JJ, Clapham DE. 2012. The control of male fertility by spermatozoan ion channels. Annu Rev Physiol 74:453-75. doi: 10.1146/annurev-physiol-020911-153258.

Mackinnon R, Miller C. 1988. Mechanism of charybdotoxin block of the high-conductance, Ca2+-activated K+ channel. J Gen Physiol 91:335-49. doi: 10.1085/jgp.91.3.335.

Mannowetz N, Wandernoth P, Hornung J, Ruffing U, Raubuch M, Wennemuth G. 2011. Early activation of sperm by $\mathrm{HCO}(3)(-)$ is regulated hormonally in the murine uterus. Int J Androl 34:153-64. doi: 10.1111/j.13652605.2010.01067.x.

Marty A. 1981. Ca-dependent K channels with large unitary conductance in chromaffin cell membranes. Nature 291:497-500. doi: 10.1038/291497a0.

Meera P, Wallner M, Toro L. 2000. A neuronal beta subunit (KCNMB4) makes the large conductance, voltageand $\mathrm{Ca} 2+$-activated $\mathrm{K}+$ channel resistant to charybdotoxin and iberiotoxin. Proc Natl Acad Sci USA 97:5562-7. doi: 10.1073/pnas.100118597.

Meizel S, Deamer DW. 1978. The pH of the hamster sperm acrosome. J Histochem Cytochem 26:98-105. doi: 10.1177/26.2.24069.

Meredith AL, Thorneloe KS, Werner ME, Nelson MT, Aldrich RW. 2004. Overactive bladder and incontinence in the absence of the BK large conductance Ca2+-activated K+ channel. J Biol Chem 279:36746-52. doi: 10.1074/ jbc.M405621200.

Miller C, Moczydlowski E, Latorre R, Phillips M. 1985. Charybdotoxin, a protein inhibitor of single Ca2+-activated K+ channels from mammalian skeletal muscle. Nature 313:316-8. doi: 10.1038/313316a0.

Moss GW, Marshall J, Morabito M, Howe JR, Moczydlowski E. 1996. An evolutionarily conserved binding site for serine proteinase inhibitors in large conductance calcium-activated potassium channels. Biochemistry 35:16024-35. doi: 10.1021/bi961452k.

Navarro B, Kirichok Y, Clapham DE. 2007. KSper, a pH-sensitive K+ current that controls sperm membrane potential. Proc Natl Acad Sci USA 104:7688-92. doi: 10.1073/pnas.0702018104.

Pallotta BS, Magleby KL, Barrett JN. 1981. Single channel recordings of Ca2+-activated K+ currents in rat muscle cell culture. Nature 293:471-4. doi: 10.1038/293471a0.

Ren D, Navarro B, Perez G, Jackson AC, Hsu S, Shi Q, et al. 2001. A sperm ion channel required for sperm motility and male fertility. Nature 413:603-9. doi: 10.1038/35098027. 
Ren D, Xia J. 2010. Calcium signaling through CatSper channels in mammalian fertilization. Physiology (Bethesda) 25:165-75. doi: 10.1152/physiol.00049.2009.

Salkoff L, Butler A, Ferreira G, Santi C, Wei A. 2006. High-conductance potassium channels of the SLO family. Nat Rev Neurosci 7:921-31. doi: 10.1038/nrn1992.

Sanchez M, McManus OB. 1996. Paxilline inhibition of the alpha-subunit of the high-conductance calcium-activated potassium channel. Neuropharmacology 35:963-8. doi: 10.1016/0028-3908(96)00137-2.

Santi CM, Martinez-Lopez P, de la Vega-Beltran JL, Butler A, Alisio A, Darszon A, et al. 2010. The SLO3 sperm-specific potassium channel plays a vital role in male fertility. FEBS Lett 584:1041-6. doi: 10.1016/j.febslet.2010.02.005.

Schreiber M, Salkoff L. 1997. A novel calcium-sensing domain in the BK channel. Biophys J 73:1355-63. doi: 10.1016/S0006-3495(97)78168-2.

Schreiber M, Wei A, Yuan A, Gaut J, Saito M, Salkoff L. 1998. Slo3, a novel pH-sensitive K+ channel from mammalian spermatocytes. J Biol Chem 273:3509-16. doi: 10.1074/jbc.273.6.3509.

Schreiber M, Yuan A, Salkoff L. 1999. Transplantable sites confer calcium sensitivity to BK channels. Nat Neurosci 2:416-21. doi: 10.1038/8077.

Smith JF, Syritsyna O, Fellous M, Serres C, Mannowetz N, Kirichok Y, et al. 2013. Disruption of the principal, progesterone-activated sperm Ca2+ channel in a CatSper2-deficient infertile patient. Proc Natl Acad Sci USA 110:6823-8. doi: 10.1073/pnas.1216588110.

Solaro CR, Lingle CJ. 1992. Trypsin-sensitive, rapid inactivation of a calcium-activated potassium channel. Science 257:1694-8. doi: 10.1126/science.1529355.

Strunker T, Goodwin N, Brenker C, Kashikar ND, Weyand I, Seifert R, et al. 2011. The CatSper channel mediates progesterone-induced Ca2+ influx in human sperm. Nature 471:382-6. doi: 10.1038/nature09769.

Tang QY, Zhang Z, Xia XM, Lingle CJ. 2010. Block of mouse Slo1 and Slo3 K+ channels by CTX, IbTX, TEA, 4-AP and quinidine. Channels (Austin) 4:22-41. doi: 10.4161/chan.4.1.10481.

Uebele VN, Lagrutta A, Wade T, Figueroa DJ, Liu Y, McKenna E, et al. 2000. Cloning and functional expression of two families of beta-subunits of the large conductance calcium-activated K+ channel. J Biol Chem 275:23211-8. doi: 10.1074/jbc.M910187199.

Visconti PE, Bailey JL, Moore GD, Pan D, Olds-Clarke P, Kopf GS. 1995a. Capacitation of mouse spermatozoa. I. Correlation between the capacitation state and protein tyrosine phosphorylation. Development 121:1129-37.

Visconti PE, Moore GD, Bailey JL, Leclerc P, Connors SA, Pan D, et al. 1995b. Capacitation of mouse spermatozoa. II. Protein tyrosine phosphorylation and capacitation are regulated by a cAMP-dependent pathway. Development 121:1139-50.

Visconti PE, Stewart-Savage J, Blasco A, Battaglia L, Miranda P, Kopf GS, et al. 1999. Roles of bicarbonate, CAMP, and protein tyrosine phosphorylation on capacitation and the spontaneous acrosome reaction of hamster sperm. Biol Reprod 61:76-84. doi: 10.1095/biolreprod61.1.76.

Visconti PE, Westbrook VA, Chertihin O, Demarco I, Sleight S, Diekman AB. 2002. Novel signaling pathways involved in sperm acquisition of fertilizing capacity. J Reprod Immunol 53:133-50. doi: 10.1016/S0165-0378(01)00103-6.

Wallner M, Meera P, Toro L. 1999. Molecular basis of fast inactivation in voltage and Ca2+-activated K+ channels: a transmembrane beta-subunit homolog. Proc Natl Acad Sci USA 96:4137-42. doi: 10.1073/pnas.96.7.4137.

Wandernoth PM, Raubuch M, Mannowetz N, Becker HM, Deitmer JW, Sly WS, et al. 2010. Role of carbonic anhydrase IV in the bicarbonate-mediated activation of murine and human sperm. PLOS ONE 5:e15061. doi: 10.1371/journal.pone.0015061.

Wei AD, Gutman GA, Aldrich R, Chandy KG, Grissmer S, Wulff H. 2005. International Union of Pharmacology. LII. Nomenclature and molecular relationships of calcium-activated potassium channels. Pharmacol Rev 57:463-72. doi: 10.1124/pr.57.4.9.

Wennemuth G, Carlson AE, Harper AJ, Babcock DF. 2003. Bicarbonate actions on flagellar and Ca2+ -channel responses: initial events in sperm activation. Development 130:1317-26. doi: 10.1242/dev.00353.

Xia XM, Ding JP, Lingle CJ. 1999. Molecular basis for the inactivation of Ca2+- and voltage-dependent BK channels in adrenal chromaffin cells and rat insulinoma tumor cells. J Neurosci 19:5255-64.

Xia XM, Ding JP, Zeng XH, Duan KL, Lingle CJ. 2000. Rectification and rapid activation at low Ca2+ of Ca2+activated, voltage-dependent BK currents: consequences of rapid inactivation by a novel beta subunit. J Neurosci 20:4890-903.

Xia XM, Zhang X, Lingle CJ. 2004. Ligand-dependent activation of Slo family channels is defined by interchangeable cytosolic domains. J Neurosci 24:5585-91. doi: 10.1523/JNEUROSCI.1296-04.2004.

Yan J, Aldrich RW. 2010. LRRC26 auxiliary protein allows BK channel activation at resting voltage without calcium. Nature 466:513-6. doi: 10.1038/nature09162.

Yan J, Aldrich RW. 2012. BK potassium channel modulation by leucine-rich repeat-containing proteins. Proc Natl Acad Sci USA 109:7917-22. doi: 10.1073/pnas.1205435109.

Yang C, Zeng XH, Zhou Y, Xia XM, Lingle CJ. 2011. LRRC52 (leucine-rich-repeat-containing protein 52), a testis-specific auxiliary subunit of the alkalization-activated Slo3 channel. Proc Natl Acad Sci USA 108:19419-24. doi: 10.1073/ pnas. 1111104108

Yuan P, Leonetti MD, Pico AR, Hsiung Y, MacKinnon R. 2010. Structure of the human BK channel Ca2+-activation apparatus at 3.0 A resolution. Science 329:182-6. doi: 10.1126/science.1190414.

Zeng X, Xia XM, Lingle CJ. 2008. Species-specific differences among KCNMB3 BK beta3 auxiliary subunits: some beta3 N-terminal variants may be primate-specific subunits. J Gen Physiol 132:115-29. doi: 10.1085/ jgp.200809969.

Zeng XH, Yang C, Kim ST, Lingle CJ, Xia XM. 2011. Deletion of the Slo3 gene abolishes alkalization-activated K+ current in mouse spermatozoa. Proc Natl Acad Sci USA 108:5879-84. doi: 10.1073/pnas.1100240108. 
Zeng Y, Clark EN, Florman HM. 1995. Sperm membrane potential: hyperpolarization during capacitation regulates zona pellucida-dependent acrosomal secretion. Dev Biol 171:554-63. doi: 10.1006/dbio. 1995.1304.

Zhang X, Zeng X, Lingle CJ. 2006a. Slo3 K+ channels: voltage and pH dependence of macroscopic currents. J Gen Physiol 128:317-36. doi: 10.1085/jgp.200609552.

Zhang X, Zeng X, Xia XM, Lingle CJ. 2006b. pH-regulated Slo3 K+ channels: properties of unitary currents. J Gen Physiol 128:301-15. doi: 10.1085/jgp.200609551.

Zhou Y, Tang QY, Xia XM, Lingle CJ. 2010. Glycine311, a determinant of paxilline block in BK channels: a novel bend in the BK S6 helix. J Gen Physiol 135:481-94. doi: 10.1085/jgp.201010403. 